\title{
Spectroscopic Characterization, Molecular Modeling and DFT/TD-DFT/PCM Calculations of Novel Hydrogen-Bonded Charge Transfer Complex between Chloranilic Acid and 2-Amino-4,6-Dimethylpyridine
}

\author{
Khairia M. Al-Ahmary ${ }^{1}$, Fatimah A. Alshehri1,2, Faten M. Atlam ${ }^{3}$, Mohamed K. Awad ${ }^{3}$ \\ ${ }^{1}$ University of Jeddah, College of Science, Department of Chemistry, Jeddah, Saudi Arabia \\ ${ }^{2}$ Department of Chemistry, Faculty of Science and Arts, University of Bisha, Alnamas, Saudi Arabia \\ ${ }^{3}$ Theoretical Applied Chemistry Unit (TACU), Chemistry Department, Faculty of Science, Tanta University, Tanta, Egypt \\ Email: ^kmal-ahmary@uj.edu.sa
}

How to cite this paper: Al-Ahmary, K.M., Alshehri, F.A., Atlam, F.M. and Awad, M.K. (2020) Spectroscopic Characterization, Molecular Modeling and DFT/TD-DFT/PCM Calculations of Novel Hydrogen-Bonded Charge Transfer Complex between Chloranilic Acid and 2-Amino-4,6-Dimethylpyridine. Open Journal of Physical Chemistry, 10, 1-32.

https://doi.org/10.4236/ojpc.2020.101001

Received: December 3, 2019

Accepted: February 10, 2020

Published: February 13, 2020

Copyright $\odot 2020$ by author(s) and Scientific Research Publishing Inc. This work is licensed under the Creative Commons Attribution International License (CC BY 4.0)

http://creativecommons.org/licenses/by/4.0/

\begin{abstract}
A charge transfer hydrogen bonded complex between the electron donor (proton acceptor) 2-amino-4,6-dimethylpyridine with the electron acceptor (proton donor) chloranilic acid has been synthesized and studied experimentally and theoretically. The stability constant recorded high values indicating the high stability of the formed complex. In chloroform, ethanol, methanol and acetonitrile were found the stoichiometric ratio 1:1. The solid complex was prepared and characterized by different spectroscopy techniques. FTIR, ${ }^{1} \mathrm{H}$ and ${ }^{13} \mathrm{C}$ NMR studies supported the presence of proton and charge transfers in the formed complex. Complemented with experimental results, molecular modelling using the density functional theory (DFT) calculations was carried out in the gas, chloroform and methanol phases where the existence of charge and hydrogen transfers. Finally, a good consistency between experimental and theoretical calculations was found confirming that the applied basis set is the suitable one for the system under investigation.
\end{abstract}

\section{Keywords}

2-Amino-4,6-Dimethylpyridine, Charge Transfer, DFT, Hydrogen Bond, Molecular Modelling Computations, and Spectroscopy

\section{Introduction}

The charge transfer is an interaction between the electronic donors (low ioniza- 
tion potential) and the electronic receptors (high electronic affinity), resulting in a complex formation in solution and shows the absorption bands in the visible region of electromagnetic radiations [1] [2].

Pauling suggested that charge transfer interaction (CT) is possible when there is a hydrogen bonding between two molecules. H-bonds can occur intermolecularly as well as intramolecularly and can exist in a non-polar environment. Therefore, $\mathrm{H}$-bonds are especially important in macromolecular and biological structures, such as proteins, and nucleic acids, where they are responsible for the structure of DNA molecules [3]-[9]. Zhao et al. confirmed that the hydrogen-bonding dynamics in electronically excited states plays a leading role in various phenomena, such as photoinduced electron transfer and fluorescence [10] [11] [12].

Aminopyridine a heterogeneous aromatic ring plays an important role in the production of medical drugs and in natural and industrial pigments and plastics [13], also in the preparation of solutions regulating the measurement of $\mathrm{pH}$ of seawater [14], used in technology as optical inhibitors [15], in the preparation of known polymers [16], in the biological properties of sugars [17] and as inhibitors in biological systems [18].

Because of the importance of the aminopyridine derivatives, the aim of this work is to develop new hydrogen-linked compounds that bind the pyridine derivative 2-amino-4,6-dimethylpyridine as an electron donor with chloranilic acid as an electron acceptor in solution and in solid states. The formed complexes study uses various physicochemical techniques such as elemental analysis, UV-vis, ${ }^{1} \mathrm{H},{ }^{13} \mathrm{C}$ NMR and FT-IR spectra. In order to confirm the experimental results, a theoretical computations using the density functional theory (DFT) at the basis set B3LYP/6-31 G(d,p) will be carried out to study the ground-state properties as optimization the structure, geometrical parameters, reactivity parameters, Fukui functions and molecular electrostatic potential maps (MEP). The origin of electronic spectra and the composition of the frontier molecular orbitals will be studied using TD-DFT through the continuum polarizable solvation model PCM. The consistency between the measured and calculated results is an important aim of this work.

\section{Experimental}

Powdered 2-amino-4,6-dimethylpyridine (2-ADMeP) (purity $\geq 98 \%$ ) was obtained from Aldrich; chloranil acid (CLA) (purity $\geq 98 \%$ ) was obtained from Alfa Aesar and chloroform, ethanol, methanol and acetonitrile from Fisher were used without further purification. Standard stock solutions of 2-ADMeP $(6.0 \times$ $10^{-4} \mathrm{~mol} \cdot \mathrm{L}^{-1}$ in $\left.\mathrm{CHL}\right),\left(1.0 \times 10^{-3} \mathrm{~mol} \cdot \mathrm{L}^{-1}\right.$ in $\mathrm{MeOH}$ and $\left.\mathrm{EtOH}\right)$, and $\left(4.0 \times 10^{-4}\right.$ $\mathrm{mol} \cdot \mathrm{L}^{-1}$ in AN) with $\left(6.0 \times 10^{-4} \mathrm{~mol} \cdot \mathrm{L}^{-1} \mathrm{CLA}\right.$ in $\left.\mathrm{CHL}\right),\left(1.0 \times 10^{-3} \mathrm{~mol} \cdot \mathrm{L}^{-1} \mathrm{CLA}\right.$ in $\mathrm{MeOH}$ and $\mathrm{EtOH})$, and $\left(4.0 \times 10^{-4} \mathrm{~mol} \cdot \mathrm{L}^{-1}\right.$ CLA in AN) were immediately prepared before each series of measurements by dissolving an appropriate amount in $50 \mathrm{~mL}$ of solvent. All solutions were stored in a dark place for at least one 
week. The electronic absorption spectra of the donor, acceptor and the formed complex were measured over the wavelength range 300 to $700 \mathrm{~nm}$ using a Shimadzu UV-1800 spectrometer (Japan) connected to a Shimadzu TCC-ZUOA temperature controller unit. The infrared spectra ( $\mathrm{KBr}$ disks) in the range of 4000 to $400 \mathrm{~cm}^{-1}$ for the solid HBCT complex were recorded on Perkin-Elmer Frontier spectrometer (USA). The elemental analysis (CHN) was carried out using a Perkin-Elmer 2400 micro Analyzer (USA). The solid [2-ADMeP-CLA] HBCT complex was synthesized by adding 2-ADMeP, $(0.2 \mathrm{mmol}$ in $10 \mathrm{~mL}$ of methanol solution) to CLA $(0.2 \mathrm{mmol}$ in $10 \mathrm{~mL}$ of methanol solution). The mixed solution was allowed to evaporate at room temperature and the formed dark pink crystals were collected, washed well with methanol and dried over anhydrous calcium chloride in a desiccator. Analytical calculations for the [2-ADMeP-CLA] complex: molecular formula: $\mathrm{C}_{13} \mathrm{H}_{12} \mathrm{~N}_{2} \mathrm{O}_{4} \mathrm{Cl}_{2}$ (M/w: 331.155 $\mathrm{g} / \mathrm{mol}$ ), C, $47.15 \%$; H, 3.65\%; N, 8.46\%. Found: C, 47.01\%; H, 3.88\%; N, 8.91\%. MP: $307^{\circ} \mathrm{C}-309^{\circ} \mathrm{C}$.

\section{Computational Methods}

All DFT calculations were performed using the Gaussian 09 program [19] using the density functional theory with Becke's three parameter exchange functional [20], the Lee-Yang-Parr correlation functional (B3LYP) and the split-valence double zeta basis set with two polarized basis functions ( $d$ and p), (DFT/B3LYP) at the $6-31 \mathrm{G}(\mathrm{d}, \mathrm{p})$ [21]. The addition of these polarization functions was very important for improving the presentation of the molecular electron density. During geometry optimizations, every bond length, bond angle and dihedral angle could relax free of constraints. Many properties could be calculated using the DFT theory such as optimization energy, geometrical parameters, molecular electrostatic potential maps (MEP), reactivity parameters and HOMO, LUMO energies. TD-DFT calculations were carried out at the same level of theory (B3LYP/6-31 G(d,p)) to explain the origin of electronic spectra, using polarizable continuum solvation method PCM, PCM-TD-DFT. In PCM, the solute part lies inside the cavity, whereas the solvent part (chloroform) was represented as a structureless material. In the PCM method, the solvent was also characterized by its dielectric constant and other macroscopic parameters. GaussView5.1 and Chemcraft programs have been used to extract the calculation results, and visualize the optimized structures, the frontier molecular orbitals (FMOs) and molecular electrostatic potential (MEP) maps.

\section{Results and Discussion}

\subsection{Observation of the Charge Transfer Band}

A dark purple colour formed when adding the e-donor (H-acceptor) 2-amino4,6-dimethylpyridine (2-ADMeP) to the e-acceptor (H-donor) chloranilic acid (CLA) in the investigated solvents, acetonitrile (AN), methanol $(\mathrm{MeOH})$, ethanol (EtOH) and as well as chloroform (CHL), were used as a non-polar solvent, 
confirming the formation of stable charge transfer complex between the e-donor (2-ADMeP) and the e-acceptor (CLA). A comparative study UV-Vis spectrum between the reactants and the formed complex was estimated using the same concentration of CLA as a reference to prevent absorption overlap of the e-acceptor (CLA) with the absorption of the formed complex. Figure 1 shows the electronic absorption spectrum of CLA, 2-ADMeP and a mixture of CLA + 2- $\mathrm{ADMeP}$ in $\mathrm{CHL}, \mathrm{EtOH}, \mathrm{MeOH}$ and $\mathrm{AN}$ at the region $250-700 \mathrm{~nm}$. New absorption bands are found at 535.5, 530.5, 529.5 and $519.0 \mathrm{~nm}$ in CHL, EtOH, $\mathrm{MeOH}$ and AN, respectively. This attributed to the $n-\pi^{*}$ transition, which provides assurance over the complex formation. It is worthy to mention that the reactants do not show any absorption in the region of study, which confirms the production of a new compound with absorption maxima over $500 \mathrm{~nm}$. Meanwhile, the donor and acceptor do not influence on the spectral characteristics of the formed complex and this means neither appear absorption maximum of the donor alone and acceptor alone in this range (500.0 - $550.0 \mathrm{~nm})$, which assert the complex formation. One observes in (Figure 1) a red shift on moving from acetonitrile to chloroform, confirming the sensitivity of the formed complex to the investigated solvents polarity.

In order to study the stability of the formed complex the effect of time, temperature and e-donor concentration were investigated. In the effect of time, the absorbance was recorded for a mixture of 2-ADMeP and CLA at different times. It has been found that the absorbance was constant within 2 hours, indicating that no side chemical reaction occurs. Also, the effect of temperature on the stability of the formed complex was measured by following the absorbance of 2-ADMeP-CLA complex between of 2-ADMeP with CLA at different temperatures $\left(20^{\circ} \mathrm{C}, 25^{\circ} \mathrm{C}, 30^{\circ} \mathrm{C}, 35^{\circ} \mathrm{C}\right.$ and $\left.40^{\circ} \mathrm{C}\right)$. Figure 2 appears that the absorbance values of the complex formed were nearly constant (slight decrease) with temperature change in the various solvents, the absorption of 2-ADMeP-CLA complex increases with increasing 2-ADMeP concentration as mentioned in effect of donor concentration. Hence, from (Figure 2) room temperature the optimum temperature degree to form the charge transfer reaction.

\subsection{Stoichiometry of the Formed HBCT Complex}

The molecular composition of the formed complex (2-ADMeP-CLA) in the investigated solvents was estimated using the conventional method of continuous variations by Job's method [22] and photometric titration method [23]. Figure 3 represents the continuous variation plot where the maximum absorbance was recorded at 0.5 -mole fraction indicating the formation of a 1:1 CT complex. Figure 4 represents the photometric titration plot where two straight lines were produced intercepting at a 1:1 ratio in the system [2-ADMeP-CLA]. The same molecular composition was obtained in all investigated solvents, meaning that the solvent has no effect on the complex composition. The constant molecular composition in all solvents means also, that the same HOMO of donor interacts with same LUMO of acceptor in all investigated media. 

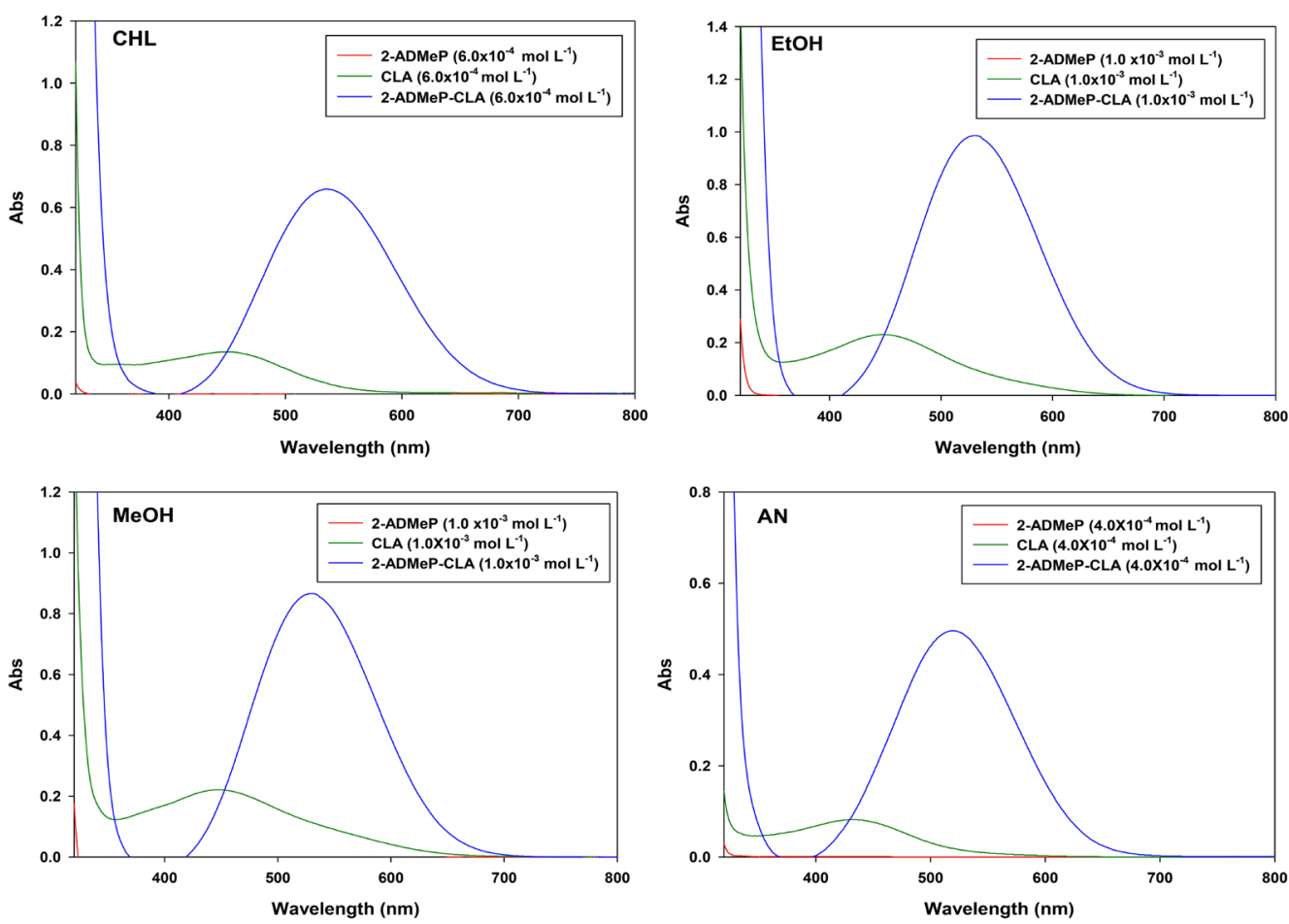

Figure 1. Observation of the CT band from electronic spectra of the reactants and the formed 2-ADMeP-CLA complex in the studied solvents.

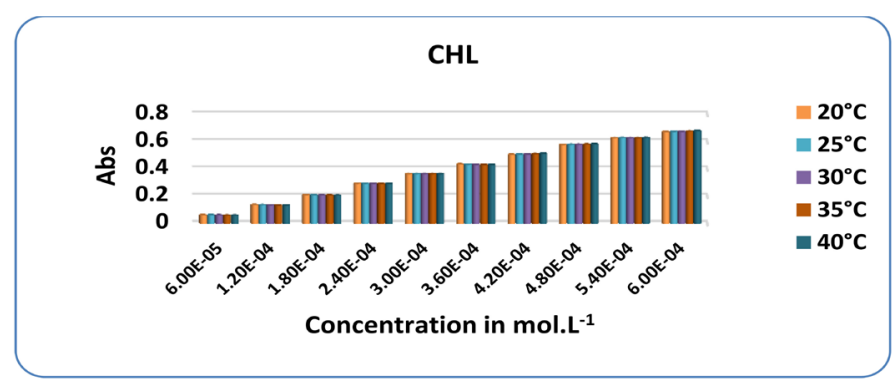

Figure 2. Effect of temperature on the 2-ADMeP-CLA complex in CHL.

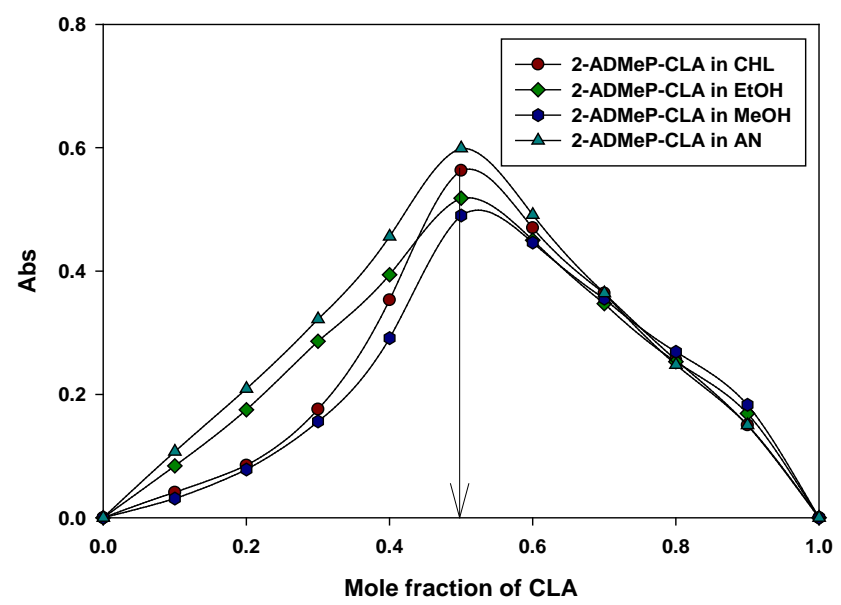

Figure 3. Job's method of continues variations of the formed complex 2-ADMeP-CLA in studied solvents. 


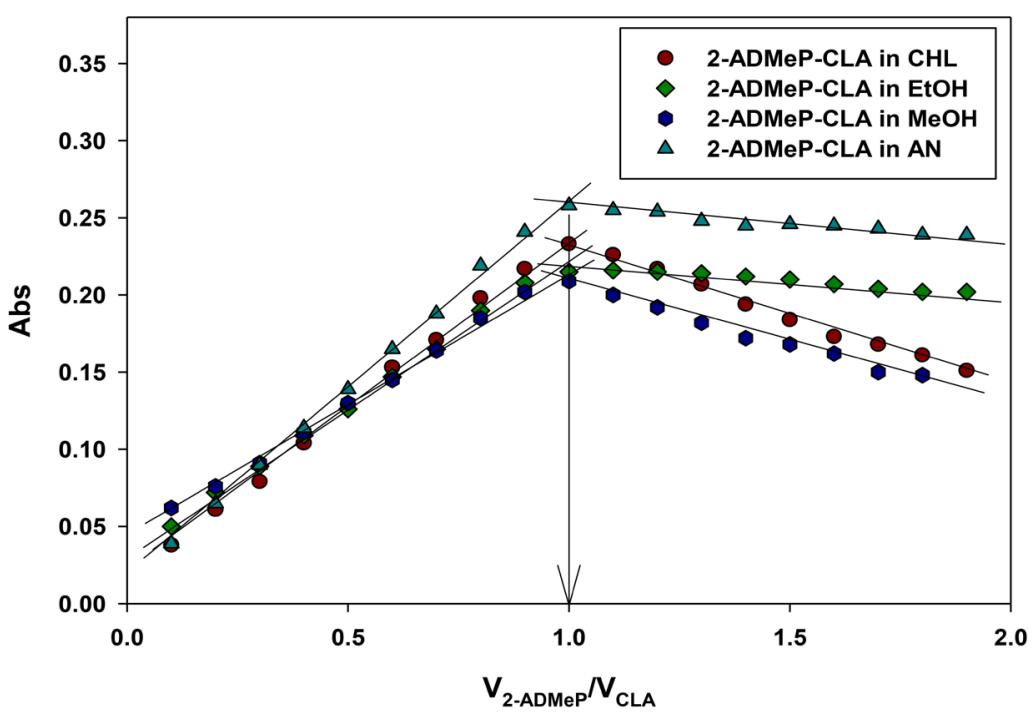

Figure 4. Photometric titration method for the formed complex 2-ADMeP-CLA in studied solvents.

\subsection{Formation Constant of the Formed Complex}

Figure 5 shows the effect of increasing the concentration of e-donor in the presence of a constant concentration of e-acceptor in CHL. It has been found that increasing the e-donor concentration increases the complex absorbance, confirming the formation of a stable complex. The method of "minimum-maximum absorbance" was proposed for the calculation of the formation constant of the formed 2-ADMeP-CLA complex in all used solvents by using Equation (1), and the molar extinction coefficient calculated using Equation (2) [24] [25]:

$$
\begin{gathered}
K_{\mathrm{CT}}=\frac{A_{\text {comp }}-A_{\min }}{C_{2-\mathrm{ADMeP}}\left(A_{\max }-A_{\text {comp }}\right)} \\
\varepsilon_{\text {max }}=\frac{A_{\max }}{C_{\text {2-ADMeP }}}
\end{gathered}
$$

where: $K_{\mathrm{CT}}$ : is the complex formation constant $\left(\mathrm{L} \cdot \mathrm{mol}^{-1}\right), \varepsilon_{\max }:$ is the molar extinction $\left(\mathrm{L} \cdot \mathrm{mol}^{-1} \cdot \mathrm{cm}^{-1}\right), A_{\text {max }}$ : is maximum absorbance of the formed complex, $A_{\text {min }}$ : is minimum absorbance of the formed complex, $A_{\text {comp }}$ : is the complex absorption values between $A_{\max }$ and $A_{\min }$, and $C_{2 \text {-ADMep }}$ is the concentration of 2-ADMeP added $\left(\mathrm{mol} \cdot \mathrm{L}^{-1}\right)$.

The results of the formation constants of 2-ADMeP-CLA complex in the studied solvents (average of the formation constants) are provided in Table 1. The results showed high values of the formation constants $\left(K_{\mathrm{CT}}\right)$ and molar extinction coefficient $(\varepsilon)$ of 2 -ADMeP-CLA complex, which confirms the high stability of the formed complex in all used solvents. The stability of the formed complex in all used solvents can be illustrated by the existence of two methyl groups in position 4 and 6 of the pyridinic ring, where the electronic donating character of methyl groups increases the electron density on the pyridinic nitrogen atom. On 
the other hand, the increasing of the electron density on the pyridinic nitrogen atom facilitates the formation of proton transfer hydrogen bonding between the $\mathrm{H}$-donor $\mathrm{CLA}(\mathrm{OH})$ and the $\mathrm{H}$-acceptor 2-ADMeP (ring nitrogen). This hydrogen bonding asserts to the stability of the formed complex.

From Table 1, one can observe the influence of the solvent type on the complex formed stability where the highest value of the formation constant of 2-ADMeP-CLA complex in acetonitrile equals to $\left(8.73 \times 10^{-3} \mathrm{~L} \cdot \mathrm{mol}^{-1}\right)$. This can be attributed that AN is the highest polar solvent, and as well do not overlap in a hydrogen bond with the donor or acceptor, which increases the formation of the complex between 2-ADMeP with CLA. On the other hand, the least value of the formation constant of the complex $\left(K_{\mathrm{CT}}\right)$ in methanol $\left(2.70 \times 10^{-3} \mathrm{~L} \cdot \mathrm{mol}^{-1}\right)$ can be assigned to the overlap of $\mathrm{MeOH}$ (H-donor) in a hydrogen bond with the nitrogen atom of 2 -ADMeP ( $\mathrm{H}$-acceptor). In the case of the non-polar solvent $\mathrm{CHL}$, the formation constant of 2-ADMeP-CLA complex has a lower value than that of acetonitrile and higher than of methanol and ethanol $\left(6.68 \times 10^{-3}\right.$ $\left.\mathrm{L} \cdot \mathrm{mol}^{-1}\right)$. These results may be due to using $10.0 \% \mathrm{AN}$ in the preparation of the e-acceptor (CLA) and indicate that the non-polar solvent is suitable for the stability of the formed complex.

\subsection{Spectroscopic Physical Data for HBCT Complex}

The stability of the formed complex can be evident from calculating the spectroscopic physical parameters. Six physical parameters were selected to express the charge transfer probability of 2-ADMeP-CLA complex. These parameters included the charge transfer energy $\left(E_{\mathrm{CT}}\right)$, are a measure the ease of charge transfer from the donor to the acceptor and include the transitions, $\mathrm{n}-\pi^{*}$ and $\pi-\pi^{*}$. The charge transfer energy can be calculated from Equation (3) [26]:

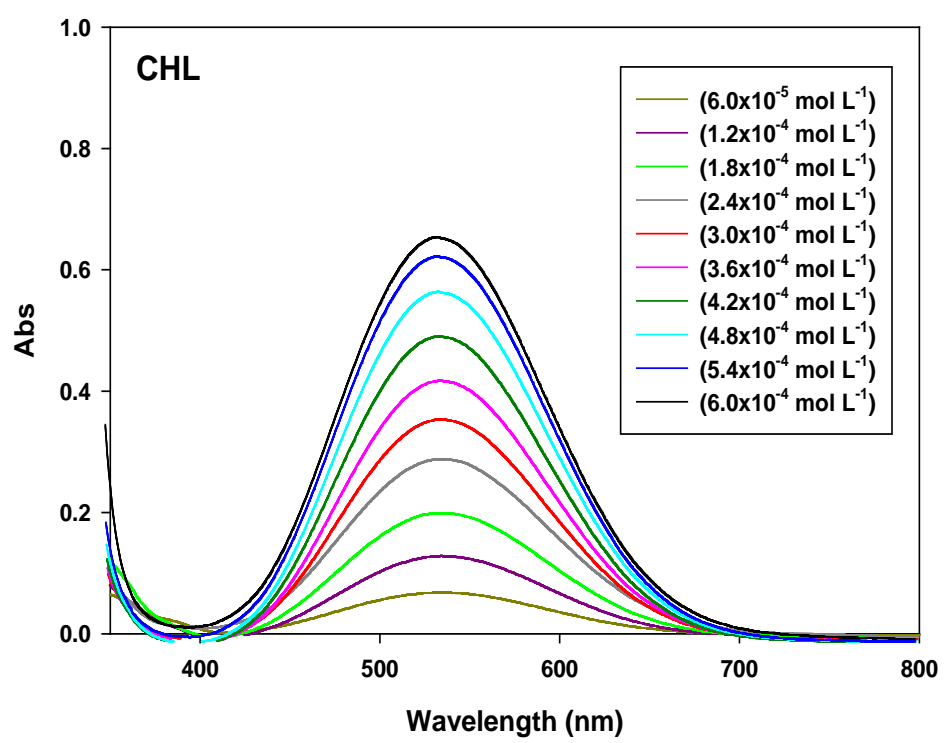

Figure 5. Effect of 2-ADMeP concentration on the formed 2-ADMeP-CLA complex absorbance with CLA $\left(6.0 \times 10^{-4} \mathrm{~mol} \cdot \mathrm{L}^{-1}\right)$. 
Table 1. Minimum-maximum absorbance data at room temperature of the 2-ADMeP-CLA complex in varied solvents.

\begin{tabular}{|c|c|c|c|c|c|c|c|c|}
\hline Solvent & $\underset{\mathrm{mol} \cdot \mathrm{L}^{-1}}{C_{\mathrm{CLA}}}$ & $\begin{array}{l}C_{2-\mathrm{ADMeP}} \\
\mathrm{mol} \cdot \mathrm{L}^{-1}\end{array}$ & $A_{\min }$ & $A_{\max }$ & $A_{\text {comp }}$ & $\begin{array}{l}K_{\mathrm{CT}} \times 10^{-3} \\
\left(\mathrm{~L} \cdot \mathrm{mol}^{-1}\right)\end{array}$ & $\begin{array}{c}\text { Average } \\
K_{\mathrm{CT}} \times 10^{-3} \\
\left(\mathrm{~L} \cdot \mathrm{mol}^{-1}\right)\end{array}$ & $\varepsilon \times 10^{-3}$ \\
\hline \multirow{8}{*}{$\begin{array}{c}\mathrm{CHL} \\
\text { at } \lambda_{\max } \\
(535.5 \\
\mathrm{nm})\end{array}$} & \multirow{8}{*}{$6.0 \times 10^{-4}$} & 0.00012 & \multirow{8}{*}{0.062} & \multirow{8}{*}{0.674} & 0.136 & 1.15 & \multirow{8}{*}{6.68} & \multirow{8}{*}{1.12} \\
\hline & & 0.00018 & & & 0.209 & 1.76 & & \\
\hline & & 0.00024 & & & 0.294 & 2.54 & & \\
\hline & & 0.00030 & & & 0.364 & 3.25 & & \\
\hline & & 0.00036 & & & 0.433 & 4.28 & & \\
\hline & & 0.00042 & & & 0.507 & 6.34 & & \\
\hline & & 0.00048 & & & 0.579 & 11.34 & & \\
\hline & & 0.00054 & & & 0.628 & 22.79 & & \\
\hline \multirow{8}{*}{$\begin{array}{l}\text { EtOH } \\
\text { at } \lambda_{\max } \\
(530.5 \\
\mathrm{nm})\end{array}$} & \multirow{8}{*}{$1.0 \times 10^{-3}$} & 0.0002 & & & 0.204 & 0.79 & \multirow{8}{*}{4.48} & \multirow{8}{*}{0.93} \\
\hline & & 0.0003 & & & 0.311 & 1.20 & & \\
\hline & & 0.0004 & & & 0.395 & 1.43 & & \\
\hline & & 0.0005 & 0000 & 7000 & 0.500 & 1.92 & & \\
\hline & & 0.0006 & 0.070 & 0.927 & 0.614 & 2.79 & & \\
\hline & & 0.0007 & & & 0.692 & 3.66 & & \\
\hline & & 0.0008 & & & 0.779 & 5.82 & & \\
\hline & & 0.0009 & & & 0.879 & 18.26 & & \\
\hline \multirow{8}{*}{$\begin{array}{l}\mathrm{MeOH} \\
\text { at } \lambda_{\max } \\
(529.5 \\
\mathrm{m})\end{array}$} & \multirow{8}{*}{$1.0 \times 10^{-3}$} & 0.0002 & & & 0.137 & 0.50 & \multirow{8}{*}{2.70} & \multirow{8}{*}{0.87} \\
\hline & & 0.0003 & & & 0.258 & 1.05 & & \\
\hline & & 0.0004 & & & 0.315 & 1.13 & & \\
\hline & & 0.0005 & 0.064 & 0.871 & 0.415 & 1.54 & & \\
\hline & & 0.0006 & & & 0.514 & 2.10 & & \\
\hline & & 0.0007 & & & 0.570 & 2.40 & & \\
\hline & & 0.0008 & & & 0.701 & 4.68 & & \\
\hline & & 0.0009 & & & 0.775 & 8.23 & & \\
\hline \multirow{8}{*}{$\begin{array}{l}\mathrm{AN} \\
\text { at } \lambda_{\max } \\
(519.0 \\
\mathrm{nm})\end{array}$} & \multirow{8}{*}{$4.0 \times 10^{-4}$} & 0.00008 & & & 0.095 & 1.66 & \multirow{8}{*}{8.73} & \multirow{8}{*}{1.20} \\
\hline & & 0.00012 & & & 0.133 & 2.14 & & \\
\hline & & 0.00016 & & & 0.199 & 3.45 & & \\
\hline & & 0.00020 & 0044 & 0,190 & 0.252 & 4.56 & & \\
\hline & & 0.00024 & 0.044 & 0.400 & 0.302 & 6.04 & & \\
\hline & & 0.00028 & & & 0.353 & 8.69 & & \\
\hline & & 0.00032 & & & 0.405 & 15.04 & & \\
\hline & & 0.00036 & & & 0.441 & 28.28 & & \\
\hline
\end{tabular}




$$
E_{\mathrm{CT}}=1243.667 / \lambda_{\mathrm{CT}}
$$

The ionization potential $\left(I_{P}\right)$ [27]: is the energy desired to eject an electron of the donor molecular orbital participating in charge transfer interaction. The ionization potential of the donor can be calculated from Equation (4):

$$
I_{P}=5.76+1.53 \times 10^{-4} v_{\mathrm{CT}}
$$

where: $\left(v_{\mathrm{CT}}\right)$ : is the wavenumber in $\mathrm{cm}^{-1}$ of 2-ADMeP-CLA complex band.

The dissociation energy of the formed charge transfer complex $(W)$ was calculated by using the following relationship (5) [28]:

$$
W=I_{P}-E_{A}-E_{\mathrm{CT}}
$$

where $\left(E_{A}\right)$ : is the electron affinity of the acceptor, ( $E_{A}$ of CLA is $\left.1.1 \mathrm{eV}\right)$.

The resonance energy $\left(R_{N}\right)$ [29]: is a factor contributing to the formed complex stability (a ground state characteristic), which can be calculated using Equation (6)

$$
\varepsilon_{\mathrm{CT}}=7.7 \times 10^{4} /\left[h v_{\mathrm{CT}} /\left[R_{N}\right]-3.5\right]
$$

where $\varepsilon_{\mathrm{CT}}$ : is the coefficient of the molar extinction of the complex at the CT absorption maximum.

The oscillator strength $(f)[30]$ : is a measurement of the probability of electron transmission to form a charge transfer band and is a dimensionless quantity. Transition dipole moment $(\mu)$ [31]: is a measure that asserts the presence of proton transfer interaction in the formed complex. The oscillator strength and the transition dipole moment can be calculated by Equations (7) and (8) as following [32]:

$$
\begin{gathered}
f=4.32 \times 10^{-9}\left[\varepsilon_{\max } \cdot \Delta v_{1 / 2}\right] \\
\mu=0.0958\left[\varepsilon_{\max } \cdot \Delta v_{1 / 2} / \bar{v}_{\max }\right]^{1 / 2}
\end{gathered}
$$

where $\Delta v_{1 / 2}$ : is the half of absorbance bandwidth, $\varepsilon_{\max }$ : is the coefficient of the molar extinction of the complex at the CT absorption maximum and $\bar{v}_{\max }$ : is the wavenumber of the formed complex at the maximum absorption.

Using the previous equations, the calculated values of the spectral physical parameters of the formed 2-ADMeP-CLA complex are listed in Table 2. The values of the charge transfer energy increased slightly and gradually on moving from chloroform to acetonitrile as shown in Table 2. A further parameter can be discussed is the potential ionization values $\left(I_{P}\right)$ of 2-ADMeP-CLA complex. The ionization potential recorded small values in all solvent, asserting the formation of a stable complex in all media, due to the ease of charge transfer from donor to acceptor. The ionization potential values for $2-\mathrm{ADMeP}$ with CLA in all solvents are nearly the same. Thus, one can conclude that the same donor molecular orbital interacts with CLA in all the studied solvents to produce the charge transfer complex. The obtained ionization potential values recorded small values due to the high basicity of $2-\mathrm{ADMeP}$ (nitrogen ring and amino group). This behaviour suggests that the electrons responsible for the basic strength of 2-ADMeP 
Table 2. Spectroscopic physical parameters of 2-ADMeP-CLA complex in studied solvents.

\begin{tabular}{ccccccc}
\hline Solvent & $E_{\mathrm{CT}}(\mathrm{eV})$ & $I_{P}(\mathrm{eV})$ & $W(\mathrm{eV})$ & $R_{N}$ & $f$ & $\mu$ (Debye) \\
\hline $\mathrm{CHL}$ & 2.3224 & 8.6171 & 5.1947 & 0.0322 & 0.7570 & 9.2803 \\
$\mathrm{EtOH}$ & 2.3443 & 8.6441 & 5.1997 & 0.0271 & 0.6442 & 8.5209 \\
$\mathrm{MeOH}$ & 2.3488 & 8.6495 & 5.2008 & 0.0256 & 0.5870 & 8.1259 \\
$\mathrm{AN}$ & 2.3963 & 8.7080 & 5.2117 & 0.0354 & 0.8087 & 9.4428 \\
\hline
\end{tabular}

(n-electrons) are the same involved in the CT interaction of 2-ADMeP with CLA in all solvents. Hence, the investigated $2-\mathrm{ADMeP}$ behaves as $\mathrm{n}$-donor towards $\pi$-acceptor (CLA), which means that the highest occupied molecular orbital (HOMO) is the non-bonding molecular orbital and the H-bond complexing sites of $2-\mathrm{ADMeP}$ is a pyridinic nitrogen atom by its lone electron pair. Therefore, the CT interaction is attributed to the promotion of non-bonding electrons of the donor 2-ADMeP to the lowest unoccupied $\pi$-molecular orbital of the acceptor CLA (LUMO). Consequently, one can deduce that the formed charge transfer complex is mainly $\mathrm{n}-\pi^{*}$ type in all solvents. It seems that the high donating power of $2-\mathrm{ADMeP}$ from the presence of two methyl groups and one amino group is presumably responsible for this situation.

Also, the dissociation energy $(W)$ of the 2 -ADMeP-CLA complex was recorded high values in all studied solvents, confirming its high stability due to the existence of both charge and proton transfer. Thus, the same donor molecular orbital interacts with CLA in the studied solvents.

From Table 2, it is clear that the highest value of the oscillator strengths was in acetonitrile, confirming the high probability of charge transfer with higher polarity solvent as acetonitrile in consisting with the stability constant values. On the other hand, the value of the oscillator strengths in CHL recorded higher value compared with $\mathrm{MeOH}$ and $\mathrm{EtOH}$, due to the presence of the hydroxyl group which leads to a hydrogen bond formation with the nitrogen atom of the pyridinic ring retarding the charge migration from the donor to the acceptor in a protic solvent.

The calculated transition dipole moment recorded high values in all solvents, confirming the formation of stable charge transfer complexation besides the proton transfer interaction. Furthermore, the transition dipole moment ( $\mu$, Debye) of the formed complex, as well as the resonance energy $\left(R_{N}\right)$, follows the same trend as the oscillator strength corresponding with the values of the formation constants $\left(K_{\mathrm{CT}}\right)$ of 2-ADMeP-CLA complex formed in all the solvents (Table 1). The values increase as follows: $\mathrm{MeOH}<\mathrm{EtOH}<\mathrm{CHL}<\mathrm{AN}$. One can deduct from this, the stability of the formed complex is attributed to the presence of two interactions, the charge transfer (CT) and proton transfer (PT). The highest probability of the charge transfer interaction and proton transfer was in the highest polarity and aprotic solvent acetonitrile compared with other solvents. 


\subsection{Determination of Thermodynamic Parameters of the HBCT Complex}

After studying the effect of temperature on the formed 2-AMDeP-CLA complex in all used solvents, minimum-maximum absorbance Equation (1) was applied to calculate the formation constant of the complex formed at different temperatures grades. In addition, Van't Hoff equation was applied to calculate the thermodynamic parameters $\left(\Delta H^{\circ}, \Delta S^{\circ}\right)$ through the following relationship [33]:

$$
\ln K_{\mathrm{CT}}=-\frac{\Delta H^{\circ}}{R T}+\frac{\Delta S^{\circ}}{R}
$$

where: $\Delta H^{\circ}$ : is enthalpy of the formed CT complex, $\Delta S$ : is the entropy of the formed CT complex, $T$ : is the absolute temperature in Kelvin and $R$ : is the gas constant $\left(8.314 \mathrm{~J} \cdot \mathrm{mol}^{-1} \cdot \mathrm{K}^{-1}\right)$.

Plotting the values of $\ln K_{\mathrm{CT}}$ versus $1000 / T$, a straight line was obtained, Figure 7. The slope and intercept were equal to $-\Delta H^{\circ} / R$ and $\Delta S^{\circ} / R$, respectively. The values of $K_{\mathrm{CT}}$ and the thermodynamic parameters in different solvents were collected in (Table 3).

Furthermore, standard Gibbs free energy change of the complexation process $\left(\Delta G^{\circ}\right)$ for 2-ADMeP-CLA complex was determined from the $K_{\mathrm{CT}}$ value at room temperature using the Equation (10) [34]:

$$
\Delta G^{\circ}=-2.303 R T \log K_{\mathrm{CT}}
$$

where $\Delta G^{\circ}$ : is the free energy change of the formed complex $\left(\mathrm{k} \cdot \mathrm{J} \cdot \mathrm{mol}^{-1}\right)$ and $K_{\mathrm{CT}}$ is the formed CT complex formation constant at $25^{\circ} \mathrm{C}$.

From Figure 6, the positive slope indicates that the CT complex formation is exothermic, reflecting the decrease in $K_{\mathrm{CT}}$ with increasing the temperature in acetonitrile (AN). From the results in Table 3, the negative value of the enthalpy is due to the exothermic reaction between donor and acceptor. The highest value of $-\Delta H^{\circ}$ of 2 -ADMeP-CLA complex was in CHL $\left(2.2 \mathrm{k} \cdot \mathrm{J} \cdot \mathrm{mol}^{-1}\right)$, attributing to the high stability of the formed 2-ADMeP-CLA complex in the non-polar solvent. It seems that the missing of interaction sites in chloroform (hydrogen bond donor or hydrogen bond acceptor sites) is responsible for this situation. Furthermore, due to the steric hindrance of dimer formation of the acetonitrile molecule, the lowest value of enthalpy was in the highest polar solvent (AN) (1.23 $\left.\mathrm{k} \cdot \mathrm{J} \cdot \mathrm{mol}^{-1}\right)$. As reported in literature reviews, when $\left(\Delta H^{\circ}<0\right)$, electrostatic interactions [35] [36] [37] are present. Therefore, Vanderwaals interactions or hydrogen bonds are the main forces between the donor and acceptor in the studied charge transfer. Therefore, the enthalpy change confirmed the presence of hydrogen bonding besides the charge transfer in the investigated 2-ADMeP-CLA complex.

One can observe in the entropy $\left(\Delta S^{\circ}\right)$ results, the highest value was recorded in acetonitrile $\left(71.3 \mathrm{~J} \cdot \mathrm{K}^{-1} \cdot \mathrm{mol}^{-1}\right)$, which is due to the dimer formation between the partial positive charge on methyl carbon of acetonitrile molecule and the partial negative charge on the nitrogen of a second one. While the lowest value 
of the entropy is listed in methanol $\left(59.7 \mathrm{~J} \cdot \mathrm{K}^{-1} \cdot \mathrm{mol}^{-1}\right)$ where the situation is linked with the short-range solvation effect. The fact is that methanol molecules favour interaction with the amino group protons of $2-\mathrm{ADMeP}$ rather than the other basic centres e.g. (ring nitrogen), resulting in lowering the steric hindrance and the $\Delta S^{\circ}$ value in methanol. The negative and high values of $\Delta G^{\circ}$ (Table 3) indicate the spontaneous and exothermic nature of the reaction between the donor and the acceptor with strong interaction. Also, the values of $\Delta G^{\circ}$ correspond with the formation constants values of the complex $\left(K_{\mathrm{CT}}\right)$, where the values increase as follows: $\mathrm{MeOH}<\mathrm{EtOH}<\mathrm{CHL}<\mathrm{AN}$, which make the donor and acceptor undergo to lose a degree of freedom or more physical strain [38].

Table 3. Thermodynamic parameter for 2-ADMeP-CLA complex formation in various solvents.

\begin{tabular}{|c|c|c|c|c|}
\hline $\begin{array}{c}\text { Temp. } \\
\qquad K\end{array}$ & $\begin{array}{l}K_{\mathrm{CT}} \times 10^{-3} \\
\left(\mathrm{~L} \cdot \mathrm{mol}^{-1}\right)\end{array}$ & $\begin{array}{c}-\Delta H^{\circ} \\
\left(\mathrm{kJ} \cdot \mathrm{mol}^{-1}\right)\end{array}$ & $\begin{array}{c}\Delta S \\
\left(\mathrm{JK}^{-1} \cdot \mathrm{mol}^{-1}\right)\end{array}$ & $\begin{array}{c}-\Delta G^{\circ} \\
\left(\mathrm{kJmol}^{-1}\right)\end{array}$ \\
\hline & & $\mathrm{CHL}$ & & \\
\hline 293.15 & 6.77 & & & \\
\hline 298.15 & 6.68 & & & \\
\hline 303.15 & 6.62 & 2.20 & 65.8 & 21.8 \\
\hline 308.15 & 6.50 & & & \\
\hline \multirow[t]{2}{*}{313.15} & 6.38 & & & \\
\hline & & $\mathrm{EtOH}$ & & \\
\hline 293.15 & 4.56 & & & \\
\hline 298.15 & 4.48 & & & \\
\hline 303.15 & 4.42 & 2.05 & 63.0 & 20.8 \\
\hline 308.15 & 4.37 & & & \\
\hline \multirow[t]{2}{*}{313.15} & 4.32 & & & \\
\hline & & $\mathrm{MeOH}$ & & \\
\hline 293.15 & 2.73 & & & \\
\hline 298.15 & 2.70 & & & \\
\hline 303.15 & 2.66 & 1.77 & 59.7 & 19.6 \\
\hline 308.15 & 2.64 & & & \\
\hline \multirow[t]{2}{*}{313.15} & 2.61 & & & \\
\hline & & AN & & \\
\hline 293.15 & 8.78 & & & \\
\hline 298.15 & 8.73 & & & \\
\hline 303.15 & 8.65 & 1.23 & 71.3 & 22.5 \\
\hline 308.15 & 8.57 & & & \\
\hline 313.15 & 8.52 & & & \\
\hline
\end{tabular}




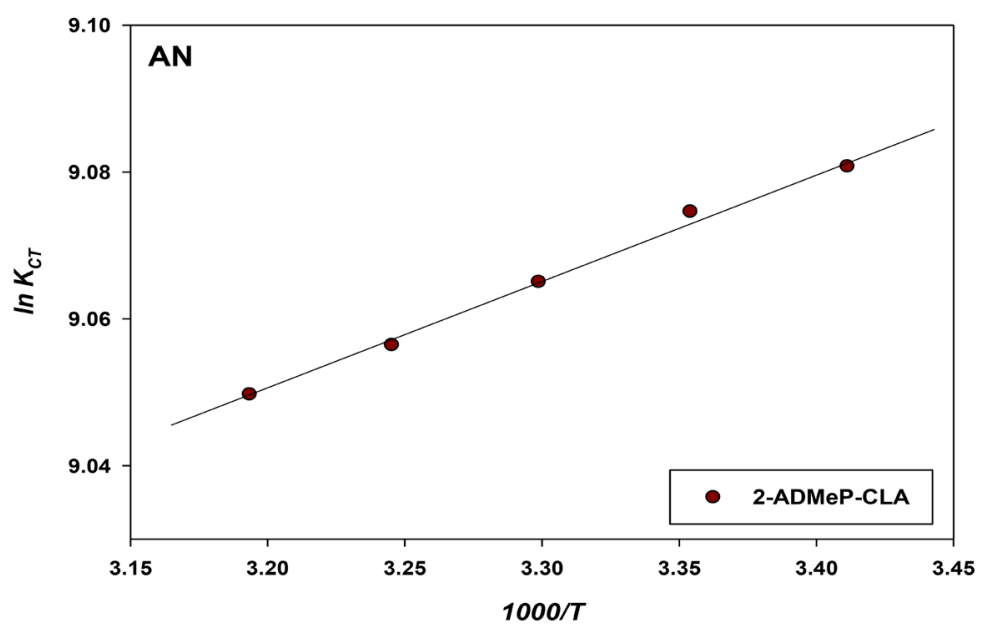

Figure 6. Van't Hoff equation of 2-ADMeP-CLA complex in AN.

\subsection{FT-IR Spectra of the Solid HBCT Complex}

The formation of 1:1 charge and proton transfer complex between 2-ADMeP with CLA was established from a comparison of the FTIR spectra of the complex with that of the reactants (2-ADMeP and CLA). The most important infrared bands of the e-donor (2-ADMeP), the e-acceptor (CLA) and the HPCT complex (2-ADMeP-CLA) are shown in Figure 7. The infrared band assignments are given in Table 4. Interestingly, the spectra of the reaction product 2-ADMeP-CLA complex contain the main infrared bands for both the reactants. This strongly supports the formation of the charge transfer complex. However, the absorbance of the donor and acceptor in the formed product showed some changes in band intensities and in some cases small shifts in the frequency wave-number values. These changes could be attributed to the expected symmetry and electronic structure modifications in both donor and acceptor units in the formed products relative to the free molecules. The infrared interpretation for the HBCT complex was dealt with as follows: the FTIR spectra of the complex are shown in Figure 7, where the asymmetric and symmetric stretching vibration of the amino group is broadened and appeared at $3299 \mathrm{~cm}^{-1}$ and $3139 \mathrm{~cm}^{-1}$ comparing with $3354 \mathrm{~cm}^{-1}$ and $3158 \mathrm{~cm}^{-1}$, respectively for $2-\mathrm{ADMeP}$ itself. The free $2-\mathrm{ADMeP}$ showed two absorption bands at 2979 and $2918 \mathrm{~cm}^{-1}$ and are safely assigned to $v_{(\mathrm{CH})}$ aromatic and aliphatic, respectively. These two bands are disappeared upon complex formation with CLA. On the other hand, the absence of $v_{(\mathrm{OH})}$ of CLA acid at $3225 \mathrm{~cm}^{-1}$ in the formed complex is due to the proton transfer from CLA to 2-ADMeP. The carbonyl group appeared at $1655 \mathrm{~cm}^{-1}$ in the complex spectrum compared with $1661 \mathrm{~cm}^{-1}$ for free CLA. This result showed that the carbonyl stretching frequency is supporting the involvement of the carbonyl group in $\mathrm{H}$-bond with the neighbouring amino group. In addition, the $v_{(\mathrm{C}-\mathrm{Cl})}$ of chloranilic acid is affected by the complex formation and it is shifted to 826 and $714 \mathrm{~cm}^{-1}$ upon complexation compared with 837 and $750 \mathrm{~cm}^{-1}$ for free CLA, confirming a charge transfer from a donor (2-ADMeP) to an acceptor (CLA). One can also 
observe (Figure 7) the presence of abroad and intense absorption in the 1600 $800 \mathrm{~cm}^{-1}$ region in the complex spectrum which confirming the presence of $\mathrm{OHN}$ hydrogen bonding between 2-ADMeP and CLA (OH ... N) [4]. An important finding from Figure 7, is the appearance of a vibrational band at 2900 $\mathrm{cm}^{-1}$ complex spectrum which could be assigned to be $v_{(\mathrm{NH}+\ldots \mathrm{O}-)}$ and supports the proton transfer process from $\mathrm{OH}$ of the acceptor (CLA) towards the ring nitrogen of the donor (2-ADMeP). Moreover, the vibrational bands of the complex were shifted compared with those of the reactants. The stretching vibrations $v_{(\mathrm{C}=\mathrm{C})}$ are shifted to $1633 \mathrm{~cm}^{-1}$ compared with 1609 and $1626 \mathrm{~cm}^{-1}$ for 2 -ADMeP and CLA, respectively. Also, $v_{(\mathrm{C}-\mathrm{NH} 2)}$ is shifted from 1446 in 2-ADMeP to 1491 $\mathrm{cm}^{-1}$ in complex spectrum, $v_{(\mathrm{C}=\mathrm{N})}$ shifted from 1351 to $1352 \mathrm{~cm}^{-1}, v_{(\mathrm{C}-\mathrm{C})}$ shifted from 1234 to $1223 \mathrm{~cm}^{-1}, v_{(\mathrm{C}-\mathrm{H})}$ out of plane shifted from 1161 to $1163 \mathrm{~cm}^{-1}, \delta_{(\mathrm{C}-\mathrm{N})}$ shifted from 989 to $986 \mathrm{~cm}^{-1}$ and $\delta_{(\mathrm{NH} 2)}$ shifted from 704 to $631 \mathrm{~cm}^{-1}$. On the other hand, $v_{\text {(C-O) }}$ shifted from 1365 to $1394 \mathrm{~cm}^{-1}, v_{\text {(C-C) }}$ shifted from 1257 to 1223 $\mathrm{cm}^{-1}, \delta_{(\mathrm{OH})}$ shifted from 976 to $986 \mathrm{~cm}^{-1}$, and $Y_{(\mathrm{C}=\mathrm{O})}$ shifted from 686 to $631 \mathrm{~cm}^{-1}$ for CLA. Hence, the infrared spectra strongly confirmed the presence of proton transfer besides the charge transfer between 2-ADMeP and CLA.

Table 4. Assignment and infrared frequencies $\left(\mathrm{cm}^{-1}\right)$ of the donor $(2-\mathrm{ADMeP})$, acceptor (CLA) and (2-ADMeP-CLA) complex.

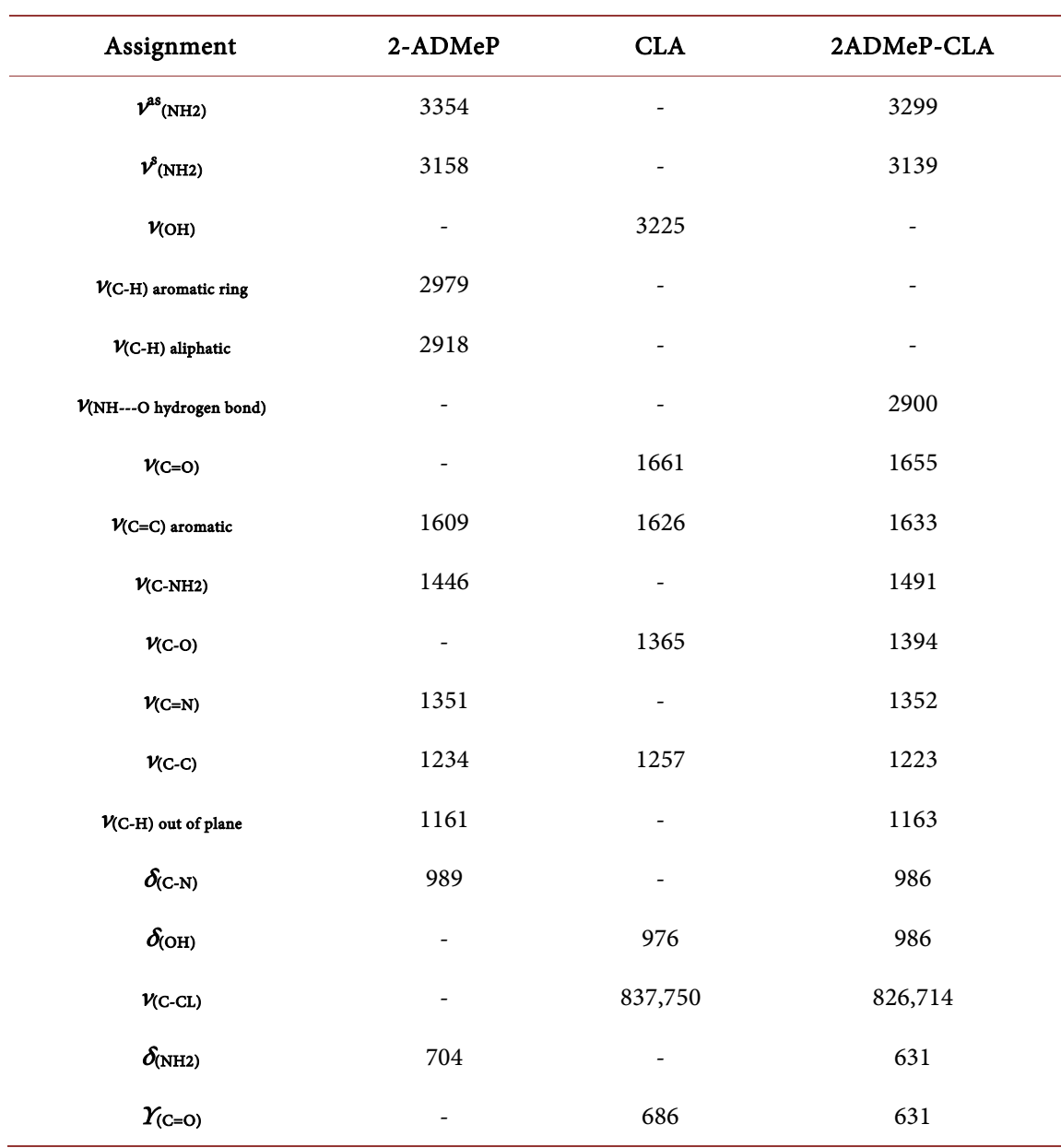



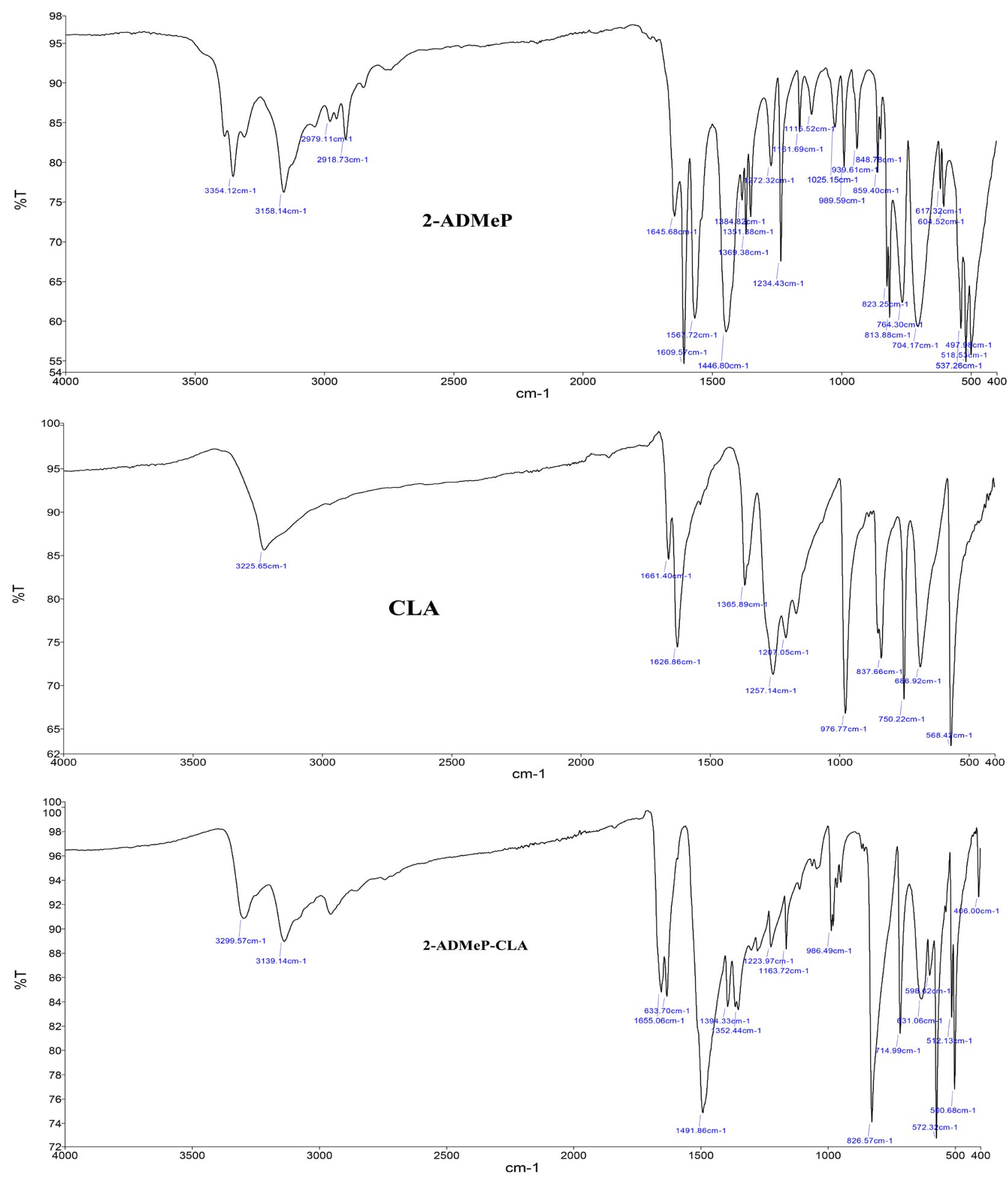

Figure 7. Infrared spectra of the donor (2-ADMeP), acceptor (CLA) and the complex (2-ADMeP-CLA) in the range $400-4000$ $\mathrm{cm}^{-1}$.

\subsection{NMR Spectra of the Solid HBCT Complex}

\subsection{1. ${ }^{1} \mathrm{H}$ NMR Spectra}

Figure 8 represents the ${ }^{1} \mathrm{H}$ NMR spectra of the e-donor 2 -ADMeP, e-acceptor 
CLA and the formed complex, 2-ADMeP-CLA, in $\mathrm{d}^{6}$-DMSO. The reactants protons appeared in the complex spectrum supporting its formation. Regarding the donor 2-ADMeP spectra, one can observe two signals at $\delta=2.08$ and $\delta=$ $2.18 \mathrm{ppm}$ refer to 6 protons of the two methyl groups. Also, the spectra of free 2-ADMeP showed the appearance of the protons of the amino group at $\delta=5.70$ ppm. Furthermore, two singlet peaks at $\delta=6.06$ and $\delta=6.19 \mathrm{ppm}$ refer to two aromatic protons of the donor. For the acceptor (CLA) from the ${ }^{1} \mathrm{H}$ NMR spectra, a broad signal was found at $\delta=8.14 \mathrm{ppm}$ attributing to two intramolecular hydrogen bonds in this molecule. Concerning the ${ }^{1} \mathrm{H}$ NMR spectra of the formed HBCT complex (2-ADMeP-CLA) from Figure 10, a very important finding is the disappearance of signal refer to $\mathrm{OH}$ proton in CLA and appeared a broad signal at $5.34 \mathrm{ppm}$, which confirms the proton migration from $\mathrm{OH}$ group in chloranilic acid towards the ring nitrogen atom in 2 -ADMeP attributed to proton transfer hydrogen bonding in the formed complex. Furthermore, the appearance of new resonance signal at $\delta=7.53 \mathrm{ppm}$ is attributed to the proton migration from the amino group of $2-\mathrm{ADMeP}$ towards the carbonyl group in chloranilic acid, confirming the participation of an amino group of 2-ADMeP in a hydrogen bond with CLA. Also, one observes from ${ }^{1} \mathrm{H}$ NMR spectra of the formed 2-ADMeP-CLA complex signals of the protons of two methyl groups were slightly downfield shifted (deshielded) to $\delta=2.29$ and $\delta=2.38$ ppm compared with $\delta=2.08$ and $\delta=2.18 \mathrm{ppm}$ for free e-donor (2-ADMeP). In addition, the doublet resonance signal of aromatic protons of donor shifted from $\delta=6.06$
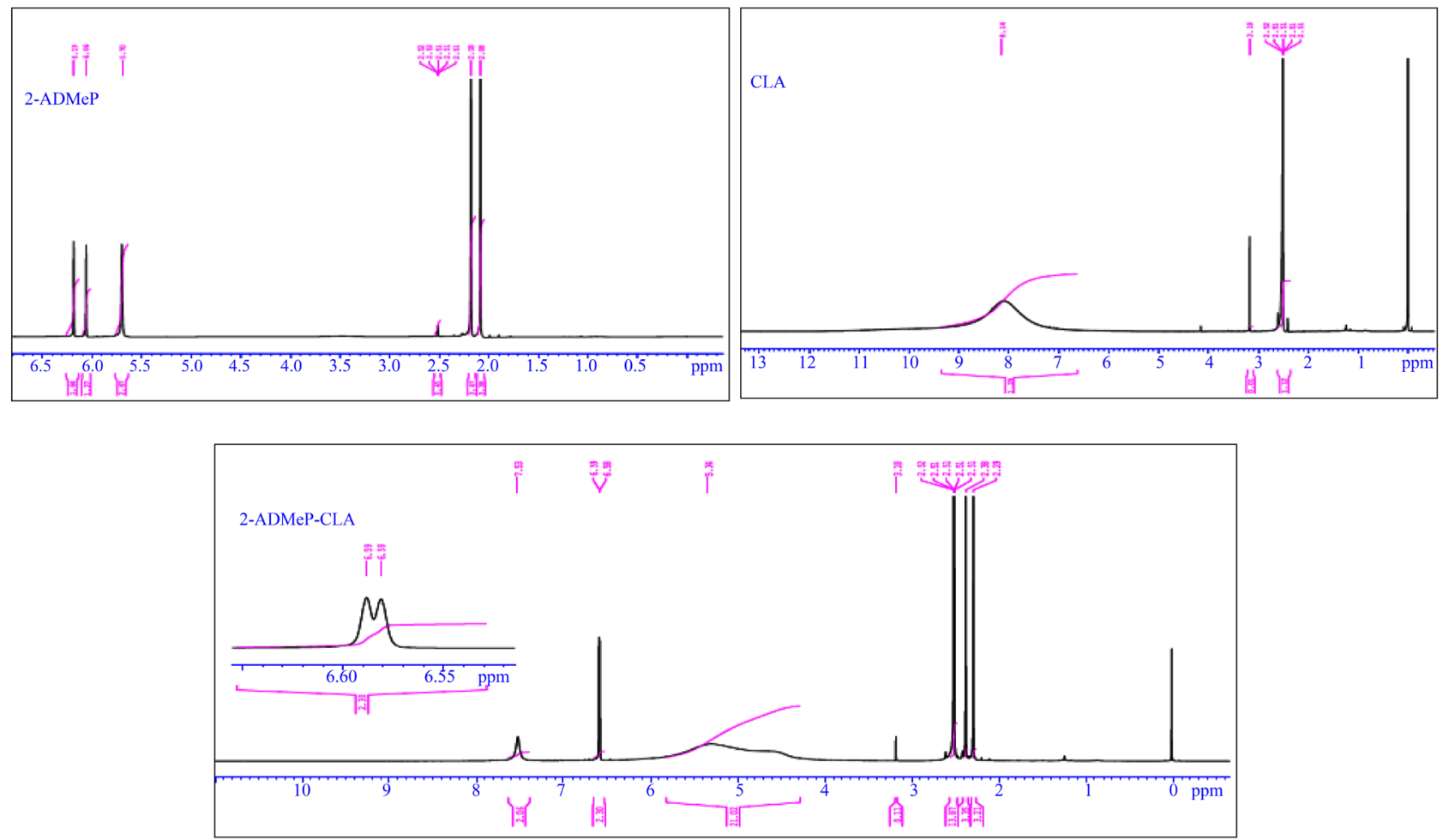

Figure 8. ${ }^{1} \mathrm{H}$ NMR spectra of 2-ADMeP, CLA and 2-ADMeP-CLA complex in DMSO-d ${ }^{6}$. 
and $\delta=6.19 \mathrm{ppm}$ to $\delta=6.58$ and $\delta=6.59 \mathrm{ppm}$, this down-field shift is expected due to the change in electronic structure upon complexation. Hence, ${ }^{1} \mathrm{H}$ NMR spectra revealed the formation of HBCT complex (2-ADMeP-CLA) in agreement with electronic and infrared spectra.

\subsection{2. ${ }^{13} \mathrm{C}$ NMR Spectra}

${ }^{13} \mathrm{C}$ NMR spectra of the donor, acceptor and the formed HBCT complex which measured in DMSO- $\mathrm{d}^{6}$ added extra information of the complex formation. The ${ }^{13} \mathrm{C}$ NMR spectra of 2-ADMeP, CLA and the formed 2-ADMeP-CLA complex are presented in Figure 9. Regarding the spectra of CLA, two signals appeared at $109.07 \mathrm{ppm}$ and $166.36 \mathrm{ppm}$ attributing to $(\mathrm{C}-\mathrm{Cl})$ and $(\mathrm{C}=\mathrm{O})$, respectively. Upon complexation, one can observe from Figure 9 that these signals are slightly different than the free CLA spectra where they appeared at $109.31 \mathrm{ppm}$ and $166.92 \mathrm{ppm}$. This result could be explained on the basis of involvement the carbonyl and the hydroxyl groups of CLA in hydrogen bond formation with ring nitrogen and $\mathrm{NH}_{2}$ group in 2-ADMeP, which confirms the charge transfer besides the hydrogen bonding in the formed complex spectra.

Concerning of 2-ADMeP carbons C(9), C(13), C(2), C(4), C(3), C(5) and C(1) atoms appeared in e-donor spectra at 20.93, 24.10, 105.55, 112.81, 147.99, 155.93 and $159.87 \mathrm{ppm}$, respectively, as shown in Table 5. Upon complexation, the resonance signals of $\mathrm{C}(9), \mathrm{C}(13), \mathrm{C}(3), \mathrm{C}(5)$ and $\mathrm{C}(1)$ are recorded a slight shift to a lower frequency (upfield) to 18.98, 21.80, 146.37, 154.25 and $156.95 \mathrm{ppm}$. On the other hand, $\mathrm{C}(2)$ and $\mathrm{C}(4)$ signals are shifted to a high frequency (downfield) to $107.73 \mathrm{ppm}$ and $114.17 \mathrm{ppm}$. This result strongly confirmed the charge migration from donor to acceptor upon complex formation. Hence, both ${ }^{1} \mathrm{H}$ and ${ }^{13} \mathrm{C}$ NMR revealed the existence of charge transfer besides hydrogen bonding in the formed spectra.

Table 5. ${ }^{13} \mathrm{C}$ NMR frequencies (ppm) of 2-ADMeP, CLA and HBCT complex in DMSO-d ${ }^{6}$.

\begin{tabular}{cccc}
\hline Atom & 2-ADMeP & CLA & $\begin{array}{c}\text { HBCT, } \\
\text { experimental }\end{array}$ \\
\hline $\mathrm{C}(1)$ & 159.87 & - & 156.95 \\
$\mathrm{C}(5)$ & 155.93 & - & 154.25 \\
$\mathrm{C}(3)$ & 147.99 & - & 146.37 \\
$\mathrm{C}(4)$ & 112.81 & - & 114.17 \\
$\mathrm{C}(2)$ & 105.55 & - & 107.73 \\
$\mathrm{C}(13)$ & 24.10 & - & 21.80 \\
$\mathrm{C}(9)$ & 20.93 & - & 18.98 \\
$\mathrm{C}(23)$ & - & 166.36 & 166.92 \\
$\mathrm{C}(25)$ & - & 109.07 & 109.31 \\
\hline
\end{tabular}



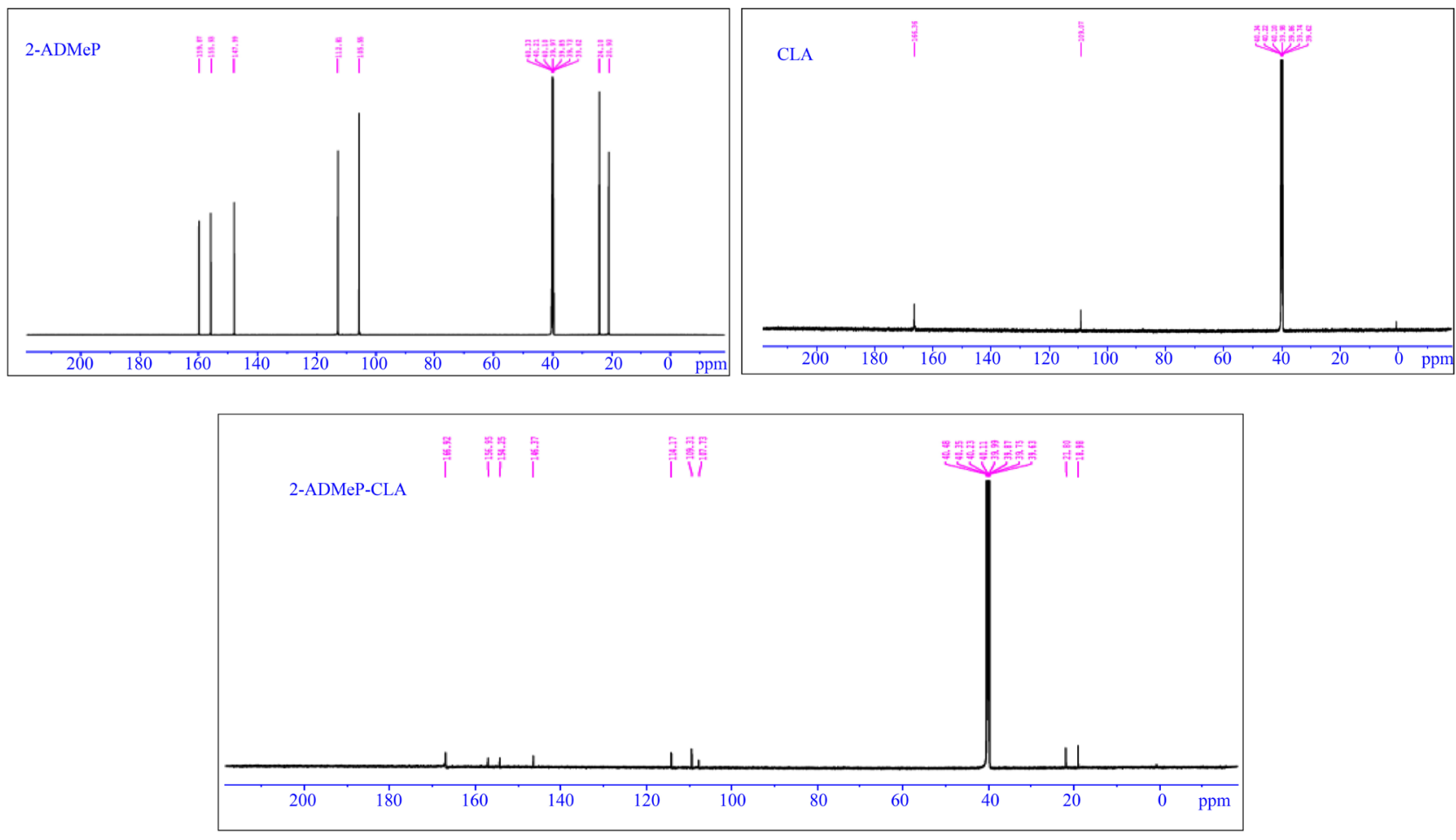

Figure 9. ${ }^{13} \mathrm{C}$ NMR spectra of 2-ADMeP, CLA and 2-ADMeP-CLA complex in DMSO-d 6 .

\subsection{Molecular Geometry Optimization of the Molecules}

Figure 10 and Figure 11 show a view of the optimized structures of the donor, acceptor and the formed complex in the gas phase including the atom numbering and hydrogen bonding interactions adopted in this study using the density functional theory DFT/B3LYP/6-31G(d,p). The calculations showed that the acid is stabilized by two intramolecular hydrogen bond interactions (Figure 10). The most stable conformer of the formed complex favours the orientation of the $\mathrm{OH}$ (CLA) towards the pyridinic like nitrogen atom of $2-\mathrm{ADMeP}(\mathrm{N} 6)$, producing a proton transfer hydrogen bonding (O21 ... H20N6). This hydrogen bonding added extra stability to the formed CT complex, 2-ADMeP-CLA. Another intramolecular hydrogen bond N17-H18-O30 was found which increases the stability of the formed complex. The complexation energy between the donor and acceptor for the minimum energy structures was calculated from the equation: $\Delta E=$ optimization energy (complex) - optimization energy (2-ADMeP-CLA) where $E_{\text {complex }}$ represents the total complex energy while $E_{(2-\mathrm{DAMeP})}$ and $E_{(\mathrm{CLA})}$ represent the energies of free donor and free acceptor. The optimization energy (total energy), the zero-point vibrational energy (the difference between the minimal energy of the system and the minimum energy of the lowest state of the system) ZPVE, the corrected optimization energy and the complexation energy are collected in Table 6. Consequently, the complexation energy recorded 18.825, 21.963 and $20.708 \mathrm{kcal} \cdot \mathrm{mol}^{-1}$ in the gas phase, methanol and chloroform, respectively, confirming the formation of stable complexes in these media. The dipole moment of the formed complex recorded higher values (16.383 and 17.279 D) in 
chloroform and methanol than that in the gas phase $(13.068 \mathrm{D})$ which enhances the proton transfer besides electron transfer in the formed complex in these media.

The hydrogen bond parameters are presented in Table 7 where one can deduce for the proton transfer hydrogen bond $\mathrm{O} 21-\mathrm{H} 20-\mathrm{N} 6$, the increase in $\mathrm{OH}$ bond length from 1.555 to 1.671 and $1.713 \AA$ on moving from gas phase to chloroform and methanol while the NH bond length decreases from $1.069 \AA$ in the gas phase to $1.046 \AA$ in chloroform and $1.042 \AA$ in methanol. This result supported the increase in hydrogen bond strength on moving from gas phase to methanol due to increasing the electrostatic interaction between $\mathrm{O}^{-}$and $\mathrm{NH}^{+}$ wings of the proton transfer hydrogen bonding. On the other hand, the OHN bond distance lays in the region 2.624 to $2.755 \AA$ of strong hydrogen bonding.

Table 6. The total optimization energy, complexation energy, zero-point vibrational energy, corrected optimization energy and thermodynamic parameters for the investigated 2-ADMeP-CLA complex.

\begin{tabular}{cccc}
\hline \multirow{2}{*}{ Parameter } & Gas phase & Methanol & Chloroform \\
\cline { 2 - 4 } & (2-ADMeP-CLA) & (2-ADMeP-CLA) & (2-ADMeP-CLA) \\
\hline $\begin{array}{c}\Delta E \\
\left(\mathrm{kcal} / \mathrm{mol}^{-1}\right)\end{array}$ & 18.825 & 21.963 & 20.708 \\
$\begin{array}{c}\mathrm{ZPVE} \\
\left(\mathrm{kcal} / \mathrm{mol}^{-1}\right)\end{array}$ & 100.732 & & 100.633 \\
$\begin{array}{c}\Delta H \\
\left(\mathrm{kcal} / \mathrm{mol}^{-1}\right)\end{array}$ & -17.570 & 100.591 & -18.825 \\
$\begin{array}{c}\Delta G \\
\left(\mathrm{kcal} / \mathrm{mol}^{-1}\right)\end{array}$ & -6.903 & -20.708 & -8.785 \\
$\begin{array}{c}\Delta S \\
\left(\mathrm{kcal} / \mathrm{mol}^{-1}\right)\end{array}$ & -37.420 & -10.040 & -36.479 \\
\hline
\end{tabular}

Table 7. Inter- and intra-molecular H-bond parameters in different solvents.

\begin{tabular}{crccc}
\hline & \multicolumn{3}{c}{ Distance $(\AA)$} & Angle \\
\cline { 2 - 5 } Solvent & \multicolumn{3}{c}{ Intermolecular H-bond O21H20N6 } \\
\cline { 2 - 5 } & 1.555 & 1.069 & 2.624 & 163.728 \\
Gas & 1.671 & 1.046 & 2.717 & 165.256 \\
Chloroform & 1.713 & 1.042 & 2.755 & 164.499 \\
Methanol & & Distance $(\AA)$ & & Angle \\
& & Intramolecular H-bond O28H29O31 \\
Solvent & O28-H29 & O31-H29 & O28O31 & O28H29O31 \\
& 0.996 & 1.804 & 2.802 & 125.111 \\
Gas & 0.998 & 1.820 & 2.817 & 124.474 \\
Chloroform & 0.997 & 1.828 & 2.824 & 124.113 \\
Methanol & & &
\end{tabular}



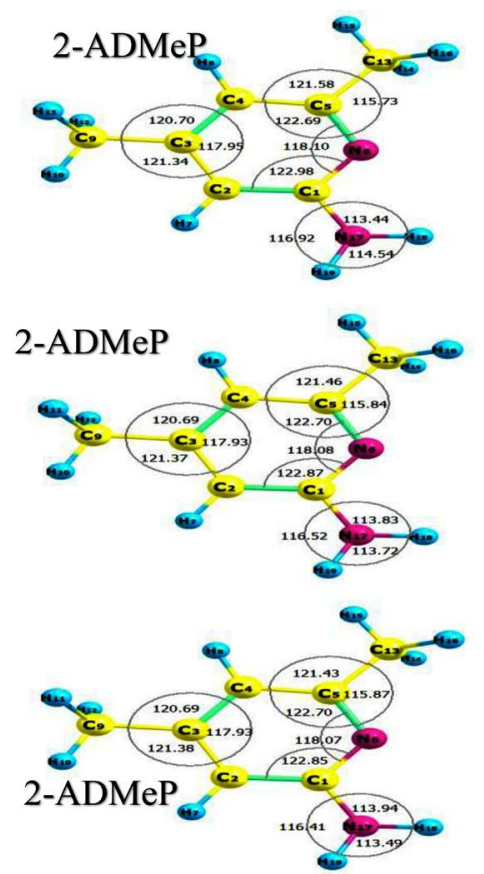

(b)

(a)
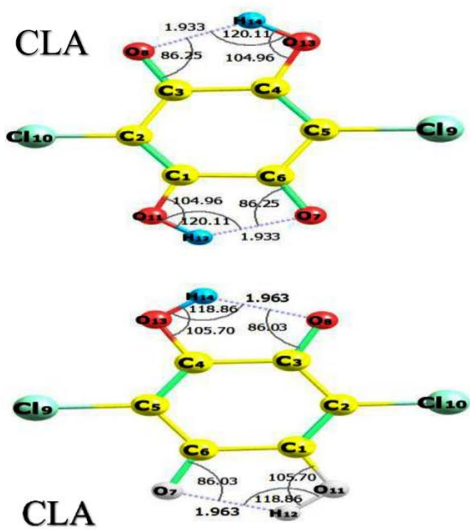

(c)

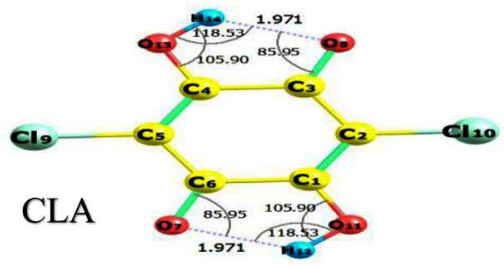

Figure 10. The optimized structures including important optimal bond lengths and bond angles of CLA and 2-ADMeP in (a) gas phase, (b) chloroform and (c) methanol.
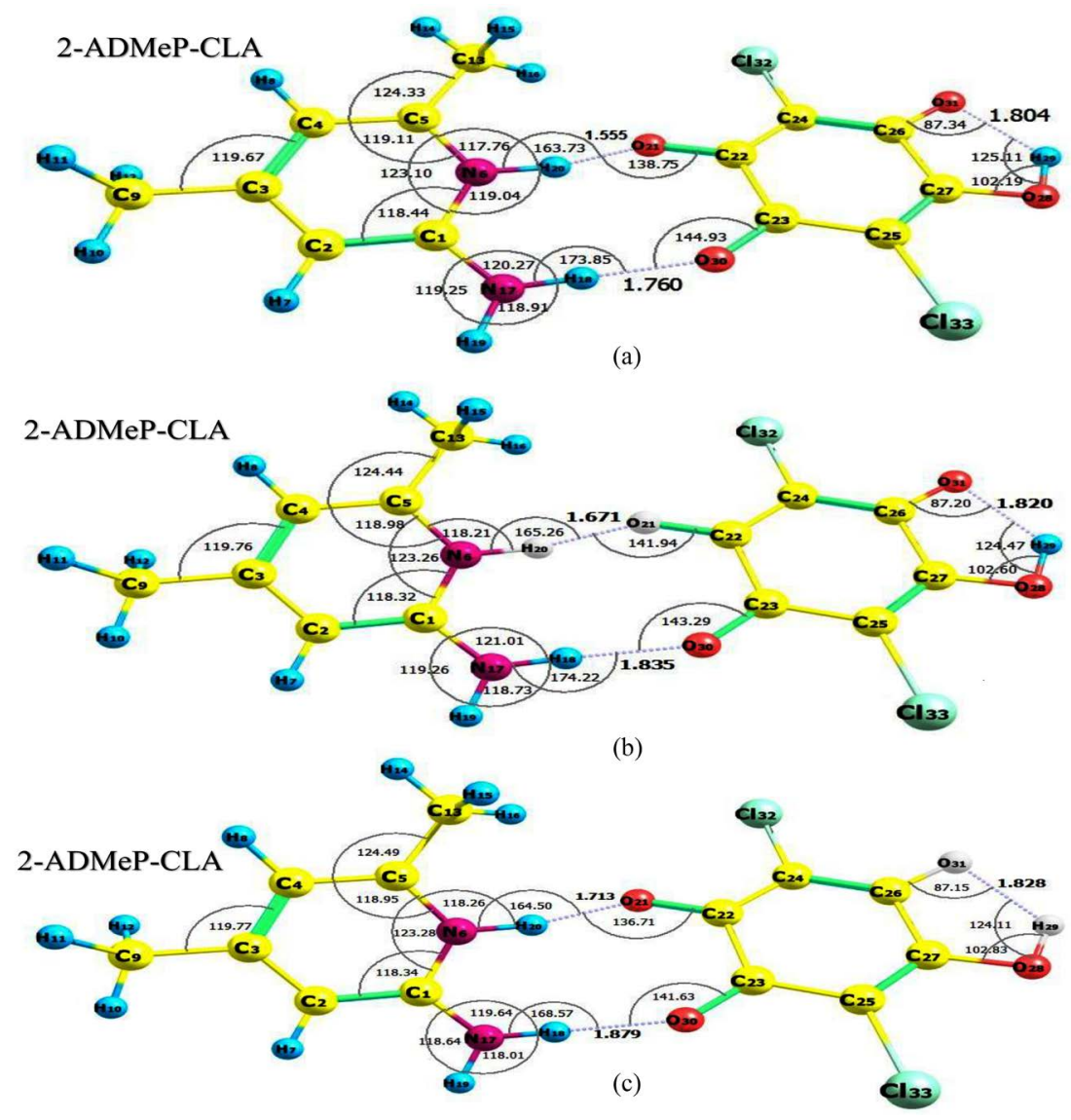

Figure 11. The optimized structures of 2-ADMeP-CLA complex including important optimal bond lengths and bond angles in (a) gas phase, (b) chloroform and (c) methanol. 
Concerning the OHN bond angle, it has been found that it lies in the range $163.728^{\circ}$ to $165.256^{\circ}$ near to the linearity that referring to a strong hydrogen bonding interaction. Concerning the intramolecular hydrogen bond O28-H29-O31, one can find, the negligible effect of solvent on its parameters where all $\mathrm{OHO}$ bond lengths are lying in the range 2.802 to $2.824 \AA$ which refers to a very strong hydrogen bond that cannot be affected by the medium (Table 7).

Figure 10 and Figure 11 represent the optimized structures of the donor, acceptor and the formed complex including the important bond angles in gas, chloroform and methanol media. It has been found that the most affecting bond angles are those near the hydrogen bonding bridge. For example, the bond angle C5-N6-C1 increases to $123.099^{\circ}, 123.264^{\circ}$ and $123.278^{\circ}$, respectively, upon complexation compared with $118.099^{\circ}, 118.079^{\circ}$ and $118.070^{\circ}$ for the free donor (2-ADMeP). This result confirmed the lowering in charge on donor part of the complex due to the expansion of the donor skeleton and the existence of proton transfer hydrogen bonding besides CT interaction. Also, this result confirmed the existence of proton transfer besides the charge transfer in the produced complex. Regarding the acceptor moiety of the complex and especially at the intramolecular hydrogen bond $\mathrm{O} 31-\mathrm{H} 29-\mathrm{O} 28$ zone, one can deduce the increase of bond angles for the complex $\left(125.111^{\circ}\right)$ relative to free CLA $\left(120.107^{\circ}\right)$. Hence, $\mathrm{H} 29-\mathrm{O} 28-\mathrm{C} 27$ bond angle is decreased to $102.192^{\circ}$ for complex compared with $104.956^{\circ}$ for free CLA, while the bond angle $\mathrm{H} 29-\mathrm{O} 31-\mathrm{C} 26$ is increased to $87.336^{\circ}$ compared with $86.254^{\circ}$ for free acid. This result confirms the CT migration from the donor to the acceptor. Hence, the calculated bond angles strongly confirmed the presence of hydrogen bonding besides charge transfer which is responsible for the high stability of the formed complex, in concordance with the experimental data.

The bond lengths of the donor and acceptor part of the complex are also affected by the complexation process (CT and H-bond interactions) as can be shown in the following examples. It has been observed that the bond lengths near the hydrogen bonding centre $(\mathrm{O} 21-\mathrm{H} 20-\mathrm{N} 6)$ are also affected. For example, C1-N6 and N6-C5 bonds are lengthened to 1.358 and $1.367 \AA$ compared with $1.338 \AA$ and $1.346 \AA$, respectively, in the gas phase due to the involvement of N6 atom in hydrogen bonding. The same situation was found in chloroform and methanol. Concerning the bonds C5-C13, and C1-N17 connecting the methyl and the amino groups with the pyridine ring, they recorded 1.500 , and $1.340 \AA$ compared with 1.508 and $1.385 \AA$, respectively, for free donor alone in the gas phase. This suggests that the amino group and one methyl group are participants in charge of the donation from 2-ADMeP towards CLA. The same behaviour was recorded in chloroform and methanol. One can also observe the increase in bond lengths of $\mathrm{C}-\mathrm{C}$ bond of pyridine ring confirms the charge transfer process from HOMO ( $\mathrm{n}$ and $\pi$ ) of the donor to LUMO $\left(\pi^{*}\right)$ of the acceptor. Regarding the acceptor part of the complex, CLA, one can observe a little increase in $\mathrm{C}-\mathrm{Cl}$ bond lengths (1.745 and $1.750 \AA$ ) for the complex relative to the acceptor alone, 
CLA (1.731 $\AA$ ), which could be attributed to the inductive effect of a chlorine atom. An important finding is the increase of $\mathrm{C}-\mathrm{C}$ bond lengths near the hydrogen bonding and the decrease for $\mathrm{C}-\mathrm{C}$ away from the hydrogen bonding. For example, C22-C23 and C22-C24 bonds (near H-bond) are lengthened to 1.557 and $1.399 \AA$, upon complexation relative to 1.522 and $1.358 \AA$, respectively, for the free acceptor. On the other hand, C24-C26 bond (away from H-bond) is shortened to $1.413 \AA$ compared with $1.452 \AA$, confirming the e-donation from donor to acceptor. Furthermore, C26-O31 bond is increased to $1.244 \AA$ compared with $1.228 \AA$ for CLA alone, while C27-O28 is shortened to $1.317 \AA$ with respect to $1.322 \AA$ for free acid, which is due to their involvement in the hydrogen bonding. Consequently, the optimal bond lengths support the existence of proton and electron transfer in the formed complex.

Regarding the dihedral angles between the two methyl and the amino groups with the pyridine ring, it has been found that the dihedral angles between the two methyl groups and the pyridine ring (C13-C5-N6-C1 and C9-C3-C2-C1) recorded $178.276^{\circ}$ and $179.805^{\circ}$, respectively, which confirms the co-planarity of these groups with the pyridine ring. The same situation was found for the amino group dihedral angle, N17-C1-N6-C5, with the pyridine ring where it recorded $179.165^{\circ}$. Hence, the electron density increases on donor moiety, leading to strong e-transfer to CLA acceptor and produces a stable complex, in concordance with the measured results.

\subsection{Quantum Chemical Parameters}

The reactivity parameters [39]-[44], such as ionization potential (I), electron affinity $\left(E_{A}\right)$, electronegativity $(\chi)$, hardness $(\eta)$, chemical potential $(\mu)$, electrophilicity index $(\omega)$, and softness, are very important descriptors to understand many aspects connected with the charge transfer reactions. All reactivity parameters could be calculated from the HOMO and LUMO energies. The definition of all the investigated reactivity parameters is described in the following equations and their values for 2-ADMeP, CLA and the 2-ADMeP-CLA complex are presented in Table 8.

$$
\begin{gathered}
\text { Ionization potential }\left(I_{P} \mathrm{eV}\right)=-E_{\text {номо }} \\
\text { Electron affinity }\left(E_{A} \mathrm{eV}\right)=-E_{\text {Lомо }} \\
\text { Electron negativity }(\chi \mathrm{eV})=\left(I_{P}+E_{A}\right) / 2 \\
\text { Hardness }(\eta \mathrm{eV})=\left(I_{P}-E_{A}\right) / 2 \\
\text { Chemical potential }(\mu \mathrm{eV})=-\chi \\
\text { Electrophilicity index }(\omega)=-\left(\mu^{2} / 2 \eta\right) \\
\text { Softness }\left(\sigma \mathrm{eV}^{-1}\right)=1 / \eta
\end{gathered}
$$

Based on the electronic reactivity parameters given in Table 8, one can deduce 
the electronic behaviour of CLA, 2-ADMeP and their complex. According to the

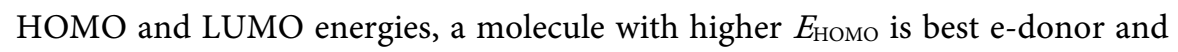
those having lower $E_{\mathrm{LUmO}}$ are the best e-acceptors. From this point of view, CLA has lower $E_{\mathrm{LUMO}}(-3.933 \mathrm{eV})$ than $2-\mathrm{ADMeP}(-0.087 \mathrm{eV})$. Consequently, CLA is the e-acceptor in its reaction with 2-ADMeP. On the other hand, 2-ADMeP has higher $E_{\mathrm{Hомо}}(-5.544 \mathrm{eV})$ and is considered as the electron donor. Furthermore, the ionization potential of 2-ADMeP recorded small values $(5.547 \mathrm{eV})$ compared with CLA $(7.024 \mathrm{eV})$, supporting its consideration as e-donor and CLA is e-acceptor. It is worth reporting that the calculated ionization potential from B3LYP is comparable with that the measured experimentally. On the other hand, the electron affinity of CLA recorded high value than that for 2 -ADMeP, confirming its consideration as an electron acceptor and $2-\mathrm{ADMeP}$ is the e-donor, this is consisting with the higher electronegativity of CLA $(5.479 \mathrm{eV})$ than that of 2-ADMeP $(2.817 \mathrm{eV})$. Moreover, CLA recorded small hardness and high softness confirming its e-acceptor capability than 2 -ADMeP. Moreover, the chemical potential is a potential index indicating the direction of electron flow among the molecule. Electron flow occurs from the system with the high chemical potential to the one with lower chemical potential. The chemical potential of 2-ADMeP recorded a high chemical potential $(-2.817 \mathrm{eV})$ relative to CLA $(-5.479 \mathrm{eV})$, hence it is considered as the e-donor and CLA is the e-acceptor. In addition, the electrophilicity of CLA is higher than that of $2-\mathrm{ADMeP}$ confirming that CLA is a better electrophile than $2-\mathrm{ADMeP}$ and is considered as the $\mathrm{e}$-acceptor and $2-\mathrm{ADMeP}$ is the e-donor. All these results revealed that $2-\mathrm{ADMeP}$

Table 8. The calculated quantum chemical parameters for the investigated compounds using the DFT method.

\begin{tabular}{|c|c|c|c|c|c|c|c|c|c|}
\hline \multirow{2}{*}{ Parameter } & \multicolumn{3}{|c|}{ Gas phase } & \multicolumn{3}{|c|}{ Methanol } & \multicolumn{3}{|c|}{ Chloroform } \\
\hline & Base & Acid & Complex & Base & Acid & Complex & Base & Acid & Complex \\
\hline HOMO $(\mathrm{eV})$ & -5.547 & -7.024 & -5.380 & -5.726 & -6.888 & -5.872 & -0.209 & -0.254 & -5.733 \\
\hline LUMO (eV) & -0.087 & -3.933 & -2.528 & -0.287 & -3.736 & -2.895 & -0.009 & -0.139 & -2.792 \\
\hline$\Delta E(\mathrm{eV})$ & 5.459 & 3.091 & 2.852 & 5.436 & 3.153 & 2.980 & 0.200 & 0.115 & 2.938 \\
\hline Dipole (D) & 1.783 & 0.000 & 13.068 & 2.446 & 0.000 & 17.279 & 2.285 & 0.002 & 16.383 \\
\hline$I_{P}(\mathrm{eV})$ & 5.547 & 7.024 & 5.380 & 5.726 & 6.888 & 5.872 & 0.209 & 0.254 & 5.733 \\
\hline$E_{A}(\mathrm{eV})$ & 0.087 & 3.933 & 2.528 & 0.287 & 3.736 & 2.895 & 0.009 & 0.139 & 2.792 \\
\hline$\chi(\mathrm{eV})$ & 2.817 & 5.479 & 3.954 & 3.007 & 5.312 & 4.384 & 0.109 & 0.197 & 4.263 \\
\hline$\mu(\mathrm{eV})$ & -2.817 & -5.479 & -3.954 & -3.007 & -5.312 & -4.384 & -0.109 & -0.197 & -4.263 \\
\hline$\eta(\mathrm{eV})$ & 2.730 & 1.546 & 1.425 & 2.720 & 1.576 & 1.489 & 0.100 & 0.058 & 1.471 \\
\hline$\sigma\left(\mathrm{eV}^{-1}\right)$ & 0.366 & 0.647 & 0.702 & 0.368 & 0.635 & 0.672 & 10.00 & 17.241 & 0.680 \\
\hline$\omega$ & 1.469 & 9.742 & 5.486 & 1.687 & 8.925 & 6.454 & 0.059 & 0.335 & 6.177 \\
\hline
\end{tabular}


is e-donor and CLA is the e-acceptor. Furthermore, as one can deduce from Table 8 , the lower energy gap of the complex $(2.852 \mathrm{eV})$, suggesting its high reactivity. The lowering is smaller in the gas phase than in chloroform or methanol, resulting in high reactivity in the gas phase with respect to solvents.

\subsection{Theoretical Electronic Spectra}

Based on the fully optimized structure of the formed complex 2-ADMeP-CLA, TD-DFT/B3LYP/6-31 G(d,p) has been used to calculate the electronic spectra in chloroform and methanol through adding polarizable continuum solvation model PCM, PCM-TD-DFT. The measured experimental values of $\lambda_{\max }$ in chloroform and methanol will be compared with those computed from PCM-TDDFT/B3LYP/6-31 G(d, p) method (Figure 12 and Figure 13), respectively. According to Franck Condon principle, the maximum absorption peak in UV-Vis is attributed to vertical excitation only. The calculated electronic spectra of HBCT complex in chloroform and methanol is shown in (Figure 14).

The measured electronic spectra of 2-ADMeP-CLA complex in chloroform and methanol exhibited absorption maxima at 535.5 and $529.5 \mathrm{~nm}$, respectively. To obtain the absorption spectra from the optimized ground state geometry, the energy was calculated for the first six vertical excitation states (S1, S2, S3, S4, S5 and S6) in chloroform and methanol. The calculated wavelengths and oscillator strengths are collected in (Table 9). The calculated absorption spectra of 2-ADMeP-CLA in chloroform consist of two intense transition bands at 550.64 $(f=0.016)$ and $320.32 \mathrm{~nm}(f=0.245)$. The transition at $550 \mathrm{~nm}$ is corresponding to $70 \%$ contribution from HOMO to LUMO ( $\mathrm{n}-\pi^{*}$ transition, ( $\varepsilon$ is lower than $1000 \mathrm{~L} \cdot \mathrm{mol}^{-1} \cdot \mathrm{cm}^{-1}$ ) while the second excitation band at $320 \mathrm{~nm}$ is corresponding to two contributions, HOMO-2 $\rightarrow$ LUMO (67\%), and HOMO $\rightarrow$ LUMO $+5(11 \%)$ $\left(\pi-\pi^{*}\right.$ transition, with $\varepsilon$ higher than $\left.1000 \mathrm{~L} \cdot \mathrm{mol}^{-1} \cdot \mathrm{cm}^{-1}\right)$. Hence, the vertical excitation energy states are $\mathrm{So} \rightarrow \mathrm{S} 1$ and $\mathrm{So} \rightarrow \mathrm{S} 6$ is the only allowed transition states with strong oscillator strengths in chloroform. In methanol, the calculated absorption spectra showed also, two intense bands at $317.59(f=0.232)$ and 540.54 $\mathrm{nm}(f=0.015)$, respectively. The first transition at $317 \mathrm{~nm}$ is attributed to the vertical transition $(\mathrm{S} 0 \rightarrow \mathrm{S} 5)$ and is corresponding to HOMO-2 $\rightarrow$ LUMO (67\%), $\mathrm{HOMO} \rightarrow \mathrm{LUMO}+4(10 \%)$ and $\mathrm{HOMO} \rightarrow \mathrm{LUMO}+5(11 \%), \pi-\pi^{*}$ transition. The second allowed transition at $540 \mathrm{~nm}(\mathrm{So} \rightarrow \mathrm{S} 1)$ is attributed to HOMO $\rightarrow$ LUMO (70\%), $\mathrm{n}-\pi^{*}$ transition. Hence, one deduces from the previous section the near measured and calculated $\lambda_{\max }$. The composition of the filled and virtual MOs (Frontier MOs) is very useful to assign the character of each electronic transition. For example, if the virtual orbital is acceptor based and the occupied orbital is donor-based, the transition is designed as CT, while it is considered as an internal transition within either donor or acceptor when both the occupied and virtual MOs are localized on the same moiety. In the formed complex both virtual and occupied MOs are located on CLA moiety confirming the presence of CT interaction. 
Table 9. The experimental and calculated energy of state $\left(E_{s}\right)$ and $\lambda_{\max }$, oscillator strength $(f)$ and contribution for the first six excitations.

\begin{tabular}{|c|c|c|c|c|c|}
\hline Medium & $\lambda_{\exp }$ & $E_{s}(\mathrm{eV})$ & $\lambda_{\text {Calc }}(\mathrm{nm})$ & $f$ & Contribution \\
\hline \multirow{6}{*}{ Gas } & & $\mathrm{S} 1(2.172)$ & 570.73 & 0.012 & HOM-LUMO \\
\hline & & $\mathrm{S} 2(2.991)$ & 414.47 & 0.003 & HOMO-LUMO+1 \\
\hline & & S3(3.099) & 400.00 & 0.000 & $\begin{array}{l}\text { HOMO-3-LUMO, } \\
\text { HOMO-2-LUMO }\end{array}$ \\
\hline & & S4(3.442) & 360.23 & 0.000 & HOMO-4-LUMO \\
\hline & & S5(3.835) & 323.32 & 0.181 & $\begin{array}{l}\text { HOMO-1-LUMO, } \\
\text { HOMO-LUMO+4 }\end{array}$ \\
\hline & & S6(3.920) & 316.27 & 0.004 & $\begin{array}{l}\text { HOMO-3-LUMO, } \\
\text { HOMO-2-LUMO }\end{array}$ \\
\hline \multirow{6}{*}{ Chloroform } & \multirow{6}{*}{535.5} & $\mathrm{~S} 1(2.252)$ & 550.64 & 0.016 & HOMO-LUMO \\
\hline & & $\mathrm{S} 2(3.012)$ & 411.65 & 0.000 & HOMO-3-LUMO \\
\hline & & S3(3.319) & 373.62 & 0.002 & HOMO-1-LUMO \\
\hline & & S4(3.527) & 351.51 & 0.000 & HOMO-4-LUMO \\
\hline & & S5(3.707) & 334.51 & 0.002 & HOMO-LUMO+1 \\
\hline & & S6(3.871) & 320.32 & 0.245 & $\begin{array}{l}\text { HOMO-2-LUMO, } \\
\text { HOMO-LUMO+5 }\end{array}$ \\
\hline \multirow{6}{*}{ Methanol } & \multirow{6}{*}{529.5} & $\mathrm{~S} 1(2.294)$ & 540.54 & 0.015 & HOMO-LUMO \\
\hline & & S2(2.991) & 414.51 & 0.000 & $\begin{array}{l}\text { HOMO-3-LUMO, } \\
\text { HOMO-1-LUMO }\end{array}$ \\
\hline & & S3(3.119) & 397.50 & 0.000 & $\begin{array}{l}\text { HOMO-3-LUMO, } \\
\text { HOMO-1-LUMO }\end{array}$ \\
\hline & & S4(3.557) & 348.54 & 0.000 & HOMO-4-LUMO \\
\hline & & S5(3.904) & 317.59 & 0.232 & $\begin{array}{l}\text { HOMO-2-LUMO, } \\
\text { HOMO-LUMO+4, } \\
\text { HOMO-LUMO+5 }\end{array}$ \\
\hline & & S6(3.954) & 313.59 & 0.001 & HOMO-LUMO+1 \\
\hline
\end{tabular}

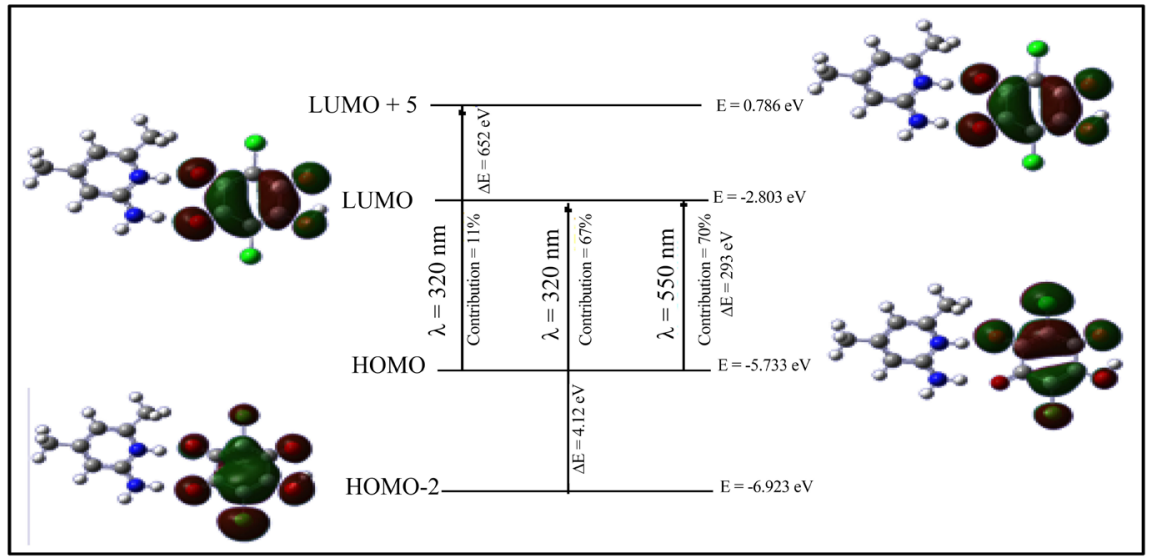

Figure 12. The charge density of HOMO and LUMO orbitals and the excitation energy $(\Delta E)$ of 2-ADMeP-CLA complex for the calculated $\lambda_{\max } 320$ and $550 \mathrm{~nm}$ in chloroform. 


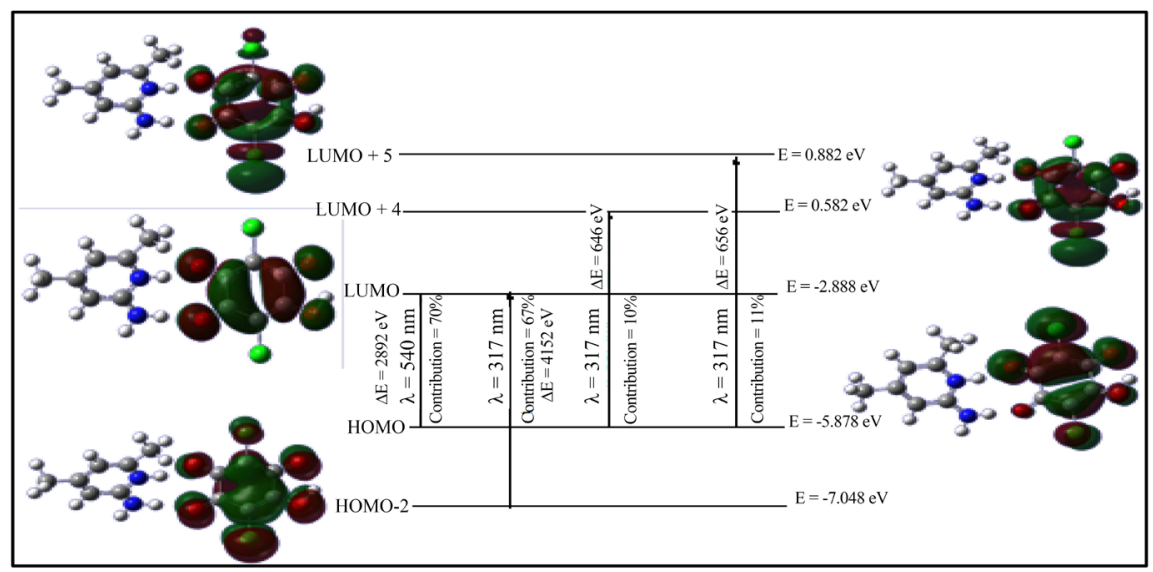

Figure 13. The charge density of HOMO and LUMO orbitals and the excitation energy $(\Delta E)$ of 2 -ADMeP-CLA complex for the calculated $\lambda_{\max } 317$ and $540 \mathrm{~nm}$ in methanol.

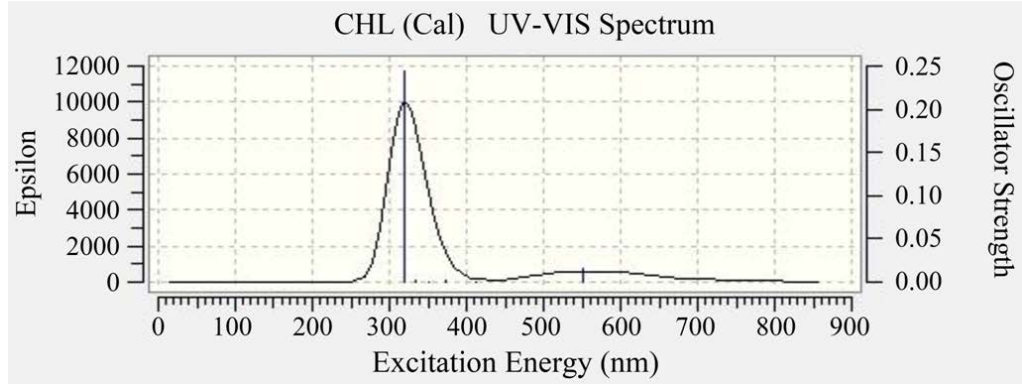

(a)

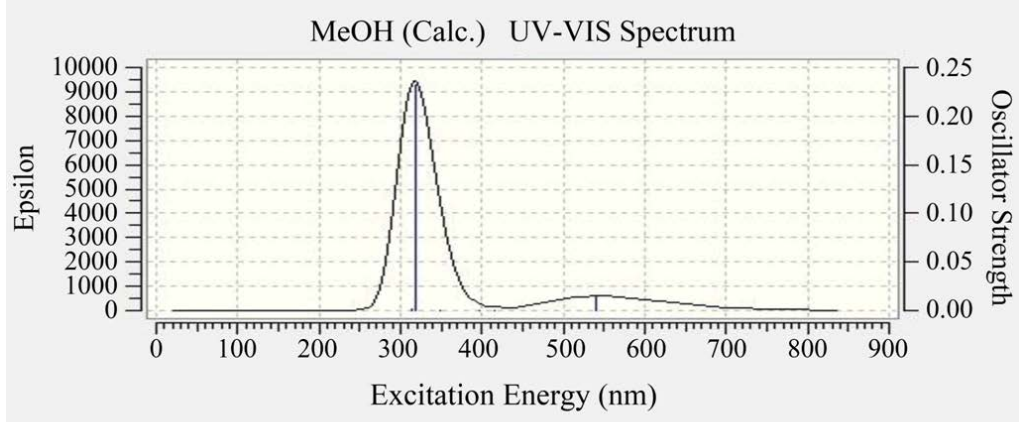

(b)

Figure 14. The calculated electronic spectra of CT complex in (a) chloroform and (b) methanol.

Figure 12 and Figure 13 represent the pictures of occupied and virtual molecular orbitals of $\mathrm{So} \rightarrow \mathrm{S} 1$ and $\mathrm{S} 0 \rightarrow \mathrm{S} 6$ in chloroform and from $\mathrm{S} 0 \rightarrow \mathrm{S} 1$ and $\mathrm{S} 0 \rightarrow \mathrm{S} 5$ in methanol. In chloroform, the major transition is shown from HOMO $\rightarrow$ LUMO excitations, where the $\mathrm{HOMO}$ is localized on $\mathrm{C}=\mathrm{C}, \mathrm{C}=\mathrm{O}, \mathrm{OH}$ and chlorine atom, while the LUMO is localized on $\mathrm{C}-\mathrm{C}, \mathrm{C}=\mathrm{O}$ and $\mathrm{OH}$ of CLA, suggesting that the computed transition at $550.64 \mathrm{~nm}$ is $\mathrm{n}-\pi^{*}$, while that at $320.32 \mathrm{~nm}$ is $\pi-\pi^{*}$ transition. Figure 13 represents the composition and virtual MOs in methanol for the first allowed transition at $317.59 \mathrm{~nm}, \mathrm{~S} 0 \rightarrow \mathrm{S} 5$, (taking into consideration the main transition (HOMO-2 $\rightarrow$ LUMO). The HOMO and HOMO-2 are localized on carbonyl oxygen, chlorine and hydroxyl oxygen ( $\pi$-electrons), while the LUMO 
and LUMO+4 are localized on the $\pi^{*}$ of CLA, supporting that this transition is attributed to ICT, $\left(\pi-\pi^{*}\right)$ transition. For the second allowed transition band in methanol at $540.54 \mathrm{~nm}(\mathrm{So} \rightarrow \mathrm{S} 1)$, one can observe that both the HOMO and LUMO are mainly present on the $\mathrm{n}$ and $\pi$ centres of CLA, confirming that the second band at $540.54 \mathrm{~nm}$ is attributed to internal $\mathrm{n}-\pi^{*}$ transition through CLA. It is worth reporting that the interference of the different MOs in HOMO and LUMO confirms the presence of hydrogen bonding in the investigated complex.

\subsection{Molecular Electrostatic Potential (MEP)}

MEP maps (Figure 15) are a good tool that describes the distribution of electrostatic potential over the surface of a molecule that explores the electrophilic and nucleophilic attack regions and hydrogen bonding interaction. The electrostatic potential is labelled by different colours where blue represents the positive region, green represents the neutral region and red represents the negative region. In our system, 2-ADMeP exhibited a red colour on the pyridinic like nitrogen supporting its contribution as hydrogen bond acceptor and n-donor (nucleophile). Orange colour is distributed among the pyridine ring confirming its contribution as $\pi$-donor in the studied CT reaction. Regarding CLA, one can see the blue colour on the $\mathrm{OH}$ groups supporting its consideration as $\mathrm{H}$-bond donor (electrophile). On the other hand, the blue colour is distributed among the CLA ring confirming its capability as $\pi$ acceptor. Considering the complex 2-ADMeP-CLA, it has been found that the blue colour covers the pyridine ring with the disappearance of the red colour. On another hand, red and orange colours cover the CLA part with the disappearance of the blue one. This confirms the charge transfer from the e-donor $2-\mathrm{ADMeP}$ towards the e-acceptor CLA. Hence, the reported MEP maps revealed the existence of charge transfer besides hydrogen bonding in the studied complex, consisting of the previous results.

\section{Conclusion}

A charge and proton transfers complexation reaction of 2-amino-4,6-dimethylpyridine as e-donor (proton acceptor) with chloranilic acid as e-acceptor (proton donor) was investigated in different solvents. The solution studies included the observation of the CT band in different solvents; we got a new band at $\lambda \max$ more $500 \mathrm{~nm}$ where the reactants are not absorbed in this region. The molecular composition of the complex was found to be 1:1 (donor: acceptor) by job and spectrophotometric methods. The stability constant was determined in the investigated solvents; they exhibited high values, confirming the formation of a stable complex. The thermodynamic parameters were calculated where high interaction is recorded in chloroform. The solid complex has been synthesized and characterized by elemental analysis to be $1: 1$, in consistency with that in solution. The formed complex has been characterized spectrophotometrically by infrared and NMR spectroscopies. They revealed the existence of charge transfer 

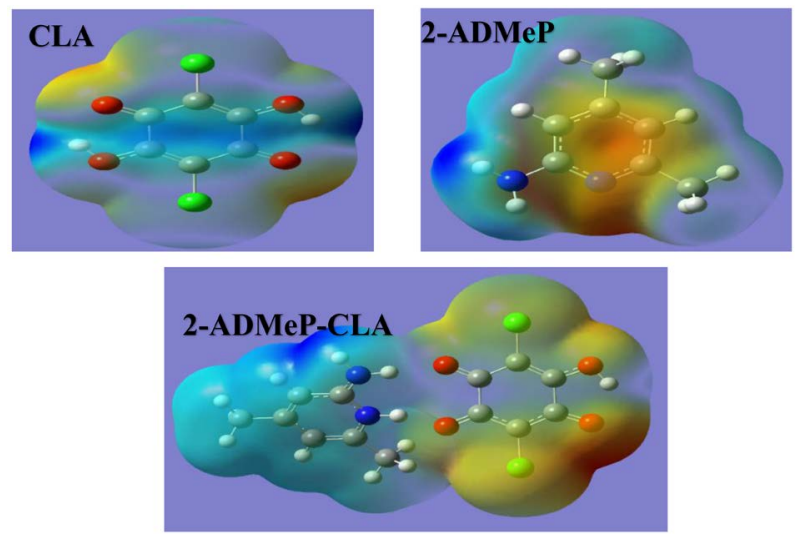

Figure 15. MEP maps of CLA, 2-ADMeP and 2-ADMeP-CLA complex.

and hydrogen bonding in the formed complex. Density functional theory (DFT) has been applied to support the experimental results. The corrected optimization energy, geometrical parameters, molecular electrostatic potential maps (MEP) and Mulliken atomic charges, strongly referred the high stability of the complex to the existence of charge transfer besides hydrogen bonding in the formed complex. The measured electronic spectra in chloroform and methanol were compared with the calculated values using TD-DFT at the same level of the theory. They came close to each other, supporting the precise computational analysis using the basis set 6-31G(d,p).

\section{Conflicts of Interest}

The authors declare no conflicts of interest regarding the publication of this paper.

\section{References}

[1] Mulliken, Robert, S. and Willis, B.P. (1969) Molecular Compounds and Their Spectra. XXI. Some General Considerations. Journal of the American Chemical Society, 91, 3409-3413. https://pubs.acs.org/doi/abs/10.1021/ja01123a067

[2] Basavaiah, K. and Charan, V.S. (2002) Spectrophotometric Determination of Astemizole and Loratadine Based on Charge-Transfer Complex Formation with Chloranilic Acid. ScienceAsia, 28, 359-364. http://www.scienceasia.org/2002.28.n4/v28 $359 \quad 364 . p d f$

[3] Habeeb, M.M. and Awad, M.K. (1995) Nuclear Quadrupole Resonance and Molecular Orbital Studies of Charge Distribution in H-Bonded Complexes of 2-Chloro4-Nitrobenzoic Acid. Magnetic Resonance in Chemistry, 33, 476-480. https://onlinelibrary.wiley.com/doi/abs/10.1002/mrc.1260330612

[4] Habeeb, M.M. (1997) Spectroscopic Studies of Proton Transfer Equilibria in Hydrogen Bonded Complexes. Applied Spectroscopy Reviews, 32, 103-140. https://www.tandfonline.com/doi/abs/10.1080/05704929508001134

[5] Amilan, D.J., Atindra, D.S., Shukla, D., Ramakrishna, G., Dipak, K., Palit, K., Hirendra, N.G. and Amitava, D. (2007) Physicochemical and Photophysical Studies on Porphyrin-Based Donor-Acceptor Systems: Effect of Redox Potentials on Ultrafast Electron-Transfer Dynamics. The Journal of Physical Chemistry B, 111, 9078-9087. 
https://pubs.acs.org/doi/abs/10.1021/jp0705830

[6] Khan, I.M. Afaq, A. and Aatif, M. (2011) Synthesis, Single-Crystal Characterization, Antimicrobial Activity and Remarkable in Vitro DNA Interaction of HydrogenBonded Proton-Transfer Complex of 1, 10-Phenanthroline with 2, 4, 6-Trinitrophenol. Journal of Photochemistry and Photobiology B: Biology, 105, 6-13. http://europepmc.org/abstract/med/21767962

[7] Khan, I.M., Afaq, A. and Kumar, S. (2013) Synthesis, Spectroscopic Characterization and Structural Investigations of a New Charge Transfer Complex of 2,6-Diaminopyridine with 3,5-Dinitrobenzoic Acid: DNA Binding and Antimicrobial Studies. Journal of Molecular Structure, 1035, 38-45.

https://www.researchgate.net/publication/256770874

https://doi.org/10.1016/j.molstruc.2012.09.016

[8] Khan, I.M., Afaq, A. and Ullah, M.F. (2013) Synthesis, Spectroscopic Investigations, Antimicrobial and DNA Binding Studies of a New Charge Transfer Complex of O-Phenylenediamine with 3,5-Dinitrosalicylic Acid. Spectrochimica Acta Part A: Molecular and Biomolecular Spectroscopy, 102, 82-87.

https://www.sciencedirect.com/science/article/abs/pii/S1386142512010220

[9] Fourmy, D., Recht, M.I., Scott, C. and Blanchard, J.D. (1996) Structure of the A site of Escherichia Coli 16S Ribosomal RNA Complexed with an Aminoglycoside Antibiotic. Science, 274, 1367-1371. https://www.ncbi.nlm.nih.gov/pubmed/8910275

[10] Andrade, S.M., Silvia, M.B. and Robert, P. (2000) Structural Changes in W/O Triton X-100/Cyclohexane-Hexanol/Water Microemulsions Probed by a Fluorescent Drug Piroxicam. Journal of Colloid and Interface Science, 226, 260-268. https://www.sciencedirect.com/science/article/abs/pii/S0021979700968218 https://doi.org/10.1006/jcis.2000.6821

[11] Bella, S.D., Fragala, I.L., Ratner, M.A. and Marks, T.J. (1993) Electron Donor-Acceptor Complexes as Potential High-Efficiency Second-Order Nonlinear Optical Materials. A Computational Investigation. Journal of the American Chemical Society, 115, 682-686.

https://scholar.google.com/scholar?cluster $=16824206174605515467 \&$ hl $=$ en $\&$ oi $=$ sch $\underline{\text { olar }}$

[12] Goldberg, G.S., Virginijus, V. and Peter, R.B. (2004) Selective Permeability of Gap Junction Channels. Biochimica et Biophysica Acta (BBA)-Biomembranes, 1662, 96-101. https://www.ncbi.nlm.nih.gov/pubmed/15033581 https://doi.org/10.1016/j.bbamem.2003.11.022

[13] Byshevsky, A.S. and Tersenov, O.A. (1994) Biochemistry for the Doctor. https://www.amazon.com/Byshevskij-Tersenov-Biohimiya-Byshevsky-Biochemistry /dp/B071KWJZZG

[14] Millero, F.J., Zhang, J.Z., Lee, K., Campbell, D.M., Campbell, D. and Zhang, J. (1993) Titration Alkalinity of Seawater. Marine Chemistry, 44, 153-165. https://www.sciencedirect.com/science/article/pii/0304420393902008

[15] Ruiz-Hitzky, E. (2001) Molecular Access to Intracrystalline Tunnels of Sepiolite Basis of a Presentation Given at Materials Discussion No. 3, 24-26 September 2000, University of Cambridge, UK. Journal of Materials Chemistry, 11, 86-91. https://pubs.rsc.org/en/content/articlelanding/2001/jm/b003197f\#!divAbstract

[16] Jie, Z. and Xiwen, H. (1999) Study of the Nature of Recognition in Molecularly Imprinted Polymer Selective for 2-Aminopyridine. Analytica Chimica Acta, 381, 85-91. https://elibrary.ru/item.asp?id=103559

[17] Roger, O., Roger, O., Colliec-Jouault, S., Ratiskol, J., Sinquin, C., Guezennec, J., 
Fischer, A.M. and Chevolot, L. (2002) Polysaccharide Labelling: Impact on Structural and Biological Properties. Carbohydrate Polymers, 50, 273-278. https://archimer.ifremer.fr/doc/2002/publication-2113.pdf

[18] Côté, B., Frenette, R., Prescott, S., Blouin, M., Brideau, C., Ducharme, Y., Friesen, R.W., Laliberte, F., Masson, P., Styhler, A. and Côté, Y.G. (2003) Substituted Aminopyridines as Potent and Selective Phosphodiesterase-4 Inhibitors. Bioorganic \& Medicinal Chemistry Letters, 13, 741-744.

http://europepmc.org/abstract/med/12270195

[19] Frisch, M.J., Trucks, G.W., Schlegel, H.B., Scuseria, G.E., Robb, M.A., Cheeseman, J.R., Scalmani, G., Barone, V., Mennucci, B., Petersson, G.A., Nakatsuji, H., Caricato, M., Li, X., Hratchian, H.P., Izmaylov, F.A., Bloino, J., Zheng, G., Sonnenberg, J.L., Hada, M., Ehara, M., Toyota, K., Fukuda, R., Hasegawa, J., Ishida, M., Nakajima, T., Honda, Y., Kitao, O., Nakai, H., Vreven, T., Montgomery Jr., J.A., Peralta, J.E., Ogliaro, F., Bearpark, M., Heyd, J.J., Brothers, E., Kudin, K.N., Staroverov, V.N., Kobayashi, R., Normand, J., Raghavachari, K., Rendell, A., Burant, J.C., Iyengar, S.S., Tomasi, J., Cossi, M., Rega, N., Millam, J.M., Klene, M., Knox, J.E., Cross, J.B., Bakken, V., Adamo, C., Jaramillo, J., Gomperts, R., Stratmann, R.E., Yazyev, O., Austin, A.G., Cammi, R., Pomelli, C., Ochterski, J.W., Martin, R.L., Morokuma, K., Zakrzewski, V.G., Voth, G.A., Salvador, P., Dannenberg, J.J., Dapprich, S., Daniels, A.D., Farkas, O., Foresman, J.B., Ortiz. J.V., Cioslowski, J. and Fox, D.J. (2009) Gaussian 09, Revision-A.02. Gaussian Inc., Wallingford, CT. http://www.rsc.org/suppdata/c5/sc/c5sc02423d/c5sc02423d1.pdf

[20] Becke, A.D. (1988) Density-Functional Exchange-Energy Approximation with Correct Asymptotic Behavior. Physical Review A, 38, 3098.

https://journals.aps.org/pra/abstract/10.1103/PhysRevA.38.3098

https://doi.org/10.1103/PhysRevA.38.3098

[21] Lee, C., Yang, W. and Parr, R.G. (1988) Development of the Colle-Salvetti Correlation-Energy Formula into a Functional of the Electron density. Physical Review. $B$, Condensed Matter, 37, 785-789. https://www.ncbi.nlm.nih.gov/pubmed/9944570 https://doi.org/10.1103/PhysRevB.37.785

[22] Job, P. (1928) Formation and Stability of Inorganic Complexes in Solution. Annales de Chimie, 9, 133-203.

https://www.scirp.org/(S(351jmbntvnsjt1aadkposzje))/reference/ReferencesPapers.a spx?ReferenceID $=1156687$

[23] Skoog, D.A., Holler, F.J. and Crouch, S.R. (2017) Principal of Instrumental Analysis. 7th Edition, Sunder College Publisher, New York.

https://www.amazon.com/Principles-Instrumental-Analysis-Douglas-Skoog/dp/130 $\underline{5577213}$

[24] Goel, A. and Ram, V.J. (2009) Natural and Synthetic 2H-Pyran-2-Ones and Their Versatility in Organic Synthesis. Tetrahedron, 65, 7865-7913.

https://www.academia.edu/19871203/Natural and synthetic 2H-pyran-2-ones an d their versatility in organic synthesis https://doi.org/10.1016/j.tet.2009.06.031

[25] Al-Ahmary, K.M. (2014) Spectroscopic Characterization of Charge Transfer Complexes of 2,3-Diaminopyridine with Chloranilic Acid and Dihydroxy-p-Benzoquinone in Polar Solvent. Spectrochimica Acta Part A: Molecular and Biomolecular Spectroscopy, 117, 635-644. https://www.sciencedirect.com/science/article/abs/pii/S1386142513010159

[26] Briegleb, G. (1964) Elektronenaffinitäten organischer Moleküle. Angewandte Chemie, 76, 326-341. 
https://onlinelibrary.wiley.com/doi/abs/10.1002/ange.19640760804 https://doi.org/10.1002/ange.19640760804

[27] Aloisi, G.G. and Pignataro, S. (1973) Molecular Complexes of Substituted Thiophens with $\sigma$ and $\pi$ Acceptors. Charge Transfer Spectra and Ionization Potentials of the Donors. Journal of the Chemical Society, Faraday Transactions 1: Physical Chemistry in Condensed Phases, 69, 534-539. https://pubs.rsc.org/-/content/articlelanding/1973/f1/f19736900534\#!divAbstract

[28] McConnell, H., Ham, J.S. and Platt, J.R. (1953) Regularities in the Spectra of Molecular Complexes. The Journal of Chemical Physics, 21, 66-70.

https://aip.scitation.org/doi/abs/10.1063/1.1698626 https://doi.org/10.1063/1.1698626

[29] Briegleb, G. and Czekalla, J. (1960) Intensity of Electron Transition Bands in Electron Donator-Acceptor Complexes. Zeitschrift für physikalische Chemie (Frankfurt), 24, 37-54.

https://www.scirp.org/(S(351jmbntvnsjt1aadkposzje))/reference/ReferencesPapers.a spx?ReferenceID $=419520$ https://doi.org/10.1524/zpch.1960.24.1 2.037

[30] Gaber, M. and Al-Shihry, S.S. (2005) Spectrophotometric and Electrical Studies of Charge Transfer Complexes of 2-Amino-1,3,4-Thiadiazole with $\pi$-Acceptors. Spectrochimica Acta Part A: Molecular and Biomolecular Spectroscopy, 62, 526-531. http://europepmc.org/abstract/med/16257756 https://doi.org/10.1016/j.saa.2005.02.005

[31] Voigt, E.M. and Reid, C. (1964) Ionization Potentials of Substituted Benzenes and Their Charge-Transfer Spectra with Tetracyanoethylene. Journal of the American Chemical Society, 86, 3930-3934. https://pubs.acs.org/doi/abs/10.1021/ja01073a005 https://doi.org/10.1021/ja01073a005

[32] Rathore, R., Hubig, S.M. and Kochi, J.K. (1997) Charge-Transfer Probes for Molecular Recognition via Steric Hindrance in Donor-Acceptor Pairs. Journal of the American Chemical Society, 119, 9393-9404. https://pubs.acs.org/doi/10.1021/ja9720319

[33] Atkins, P. and Paula, J.D. (2014) Physical Chemistry: Thermodynamics, Structure, and Change. 10th Edition, W. H. Freeman, New York.

https://www.amazon.com/Physical-Chemistry-Thermodynamics-Structure-Change /dp/1429290196/ref=sr 1 1 ?keywords=Physical-Chemistry-Thermodynamics-Struc ture\&qid $=1575103946 \& s r=8-1$

[34] Martin, A.N., Swarbrick, J. and Cammarata, A. (1993) Physical Pharmacy. 4nd Edition, Williams \& Wilkins, Baltimore, MD.

https://trove.nla.gov.au/work/6117959?q\&sort=holdings+desc\& $=1575104234019 \&$ versionId $=7081564+43371782$

[35] Kashanian, S., Gholivand, M.B., Ahmadi, F. and Ravan, H. (2008) Interaction of Diazinon with DNA and the Protective Role of Selenium in DNA Damage. DNA and Cell Biology, 27, 325-332. https://www.ncbi.nlm.nih.gov/pubmed/18447756 https://doi.org/10.1089/dna.2007.0718

[36] Ross, P.D. and Subramanian, S. (1981) Thermodynamics of Protein Association Reactions: Forces Contributing to Stability. Biochemistry, 20, 3096-3102. https://www.ncbi.nlm.nih.gov/pubmed/7248271

[37] Lerman, L.S. (1961) Structural Considerations in the Interaction of DNA and Acridines. Journal of Molecular Biology, 3, IN13-IN14. https://www.sciencedirect.com/science/article/pii/S0022283661800041

[38] Pearson, R.G. (1988) Absolute Electronegativity and Hardness: Application to In- 
organic Chemistry. Inorganic Chemistry, 27, 734-740.

https://pubs.acs.org/doi/abs/10.1021/ic00277a030

[39] Foresman, J.B. and Frisch, A.E. (1996) Exploring Chemistry with Electronic Structure Methods. 2nd Edition, Gaussian, Pittsburgh.

http://blogs.cimav.edu.mx/daniel.glossman/data/files/Libros/Exploring\%20Chemist ry\%20With\%20Electronic\%20Structure\%20Methods.pdf

[40] Chang, R. (2001) Chemistry. 7th Edition, McGraw-Hill, New York. https://www.abebooks.com/9780073656014/Chemistry-Seventh-Edition-RaymondChang-0073656011/plp

[41] Kosar, B. and Albayrak, C. (2011) Spectroscopic Investigations and Quantum Chemical Computational Study of (E)-4-Methoxy-2-[(p-Tolylimino)Methyl]Phenol. Spectrochimica Acta. Part A, Molecular and Biomolecular Spectroscopy, 78, 160-167. http://europepmc.org/abstract/med/20940104 https://doi.org/10.1016/j.saa.2010.09.016

[42] Parr, R.G. and Yang, W. (1989) Density-Functional Theory of Atoms and Molecules. Oxford University Press, New York.

[43] Parr, R.G., Von Szentpàly, L. and Liu, S.B. (1999) Electrophilicity Index. Journal of the American Chemical Society, 121, 1922-1924.

https://pubs.acs.org/doi/10.1021/ja983494x

[44] Scott, A.P. and Radom, L. (1996) Harmonic Vibrational Frequencies: An Evaluation of Hartree-Fock, Møller-Plesset, Quadratic Configuration Interaction, Density Functional Theory, and Semiempirical Scale Factors. The Journal of Physical Chemistry, 100, 16502-16513.

http://citeseerx.ist.psu.edu/viewdoc/download?doi=10.1.1.609.1172\&rep=rep1\&type $=\mathrm{pdf}$ 